
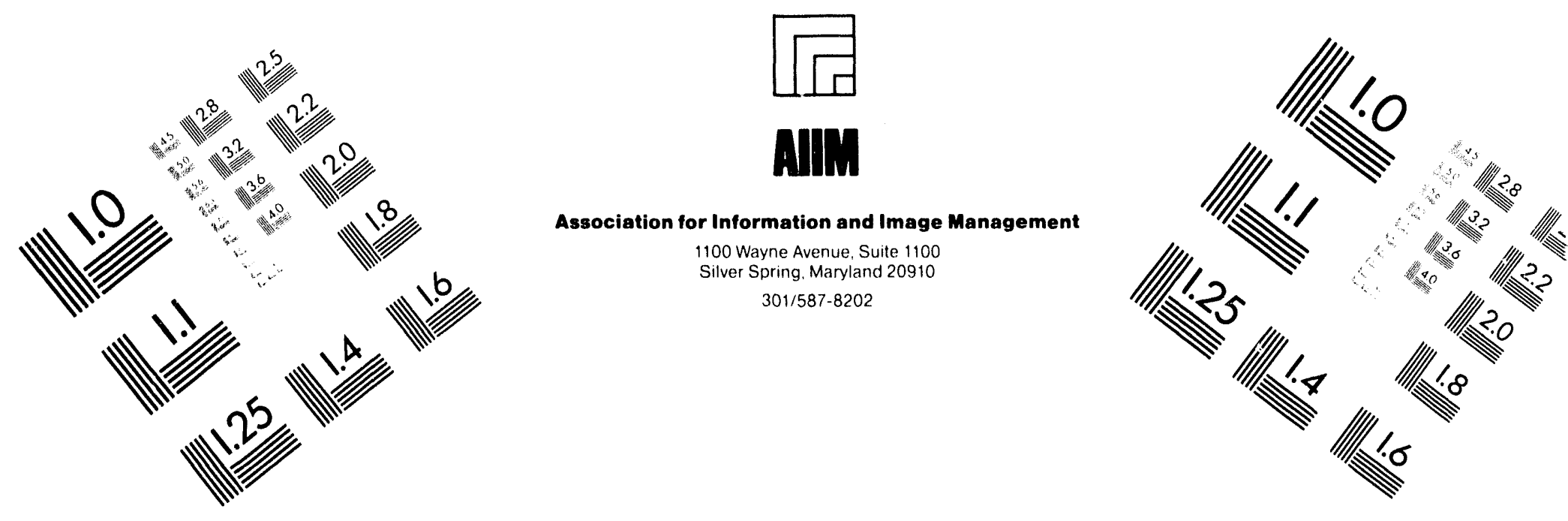

\title{
Centimeter
}

2
1 Inches
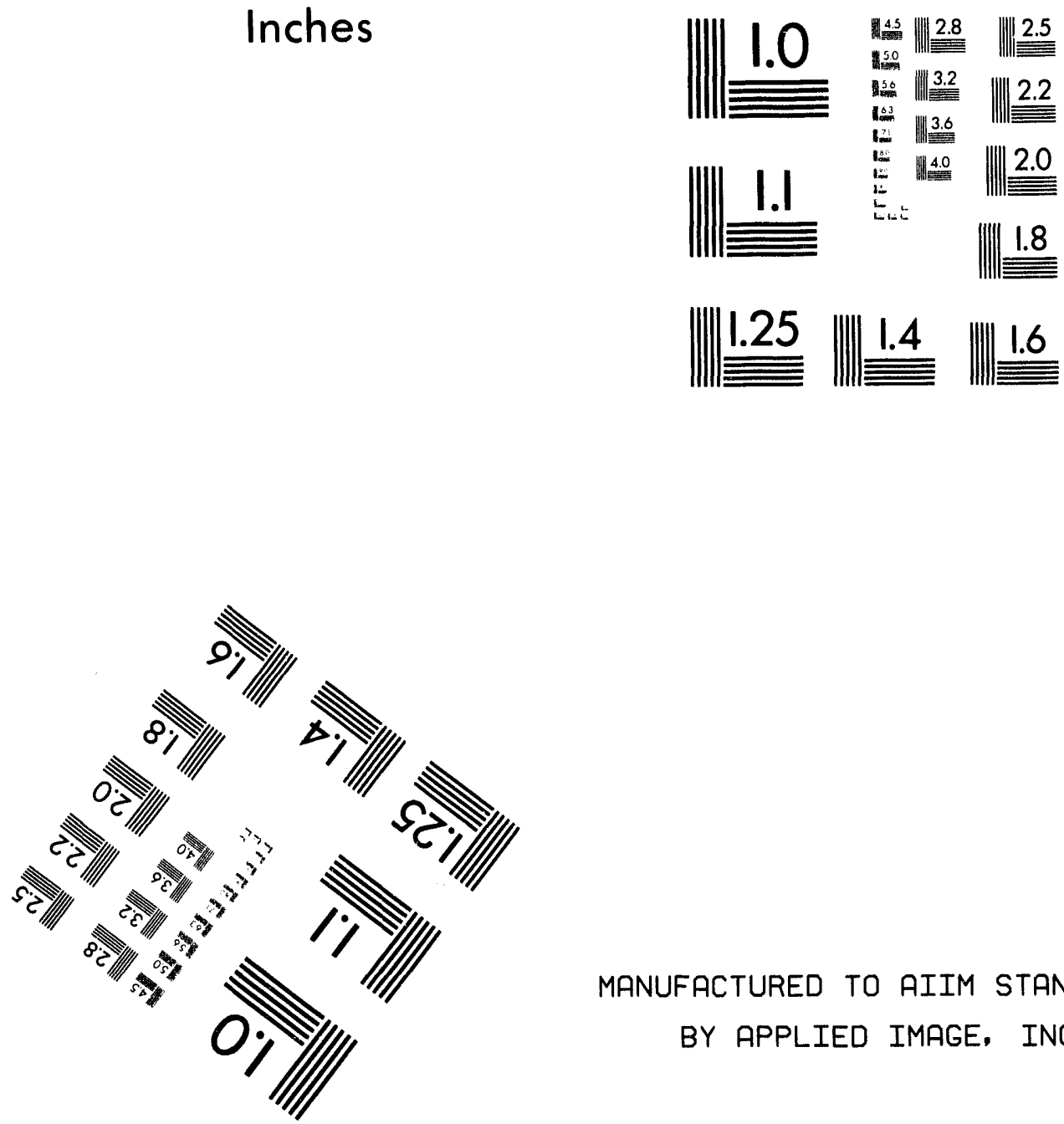

MANUFACTURED TO AIIM STANDARDS

BY APPLIED IMAGE, INC.

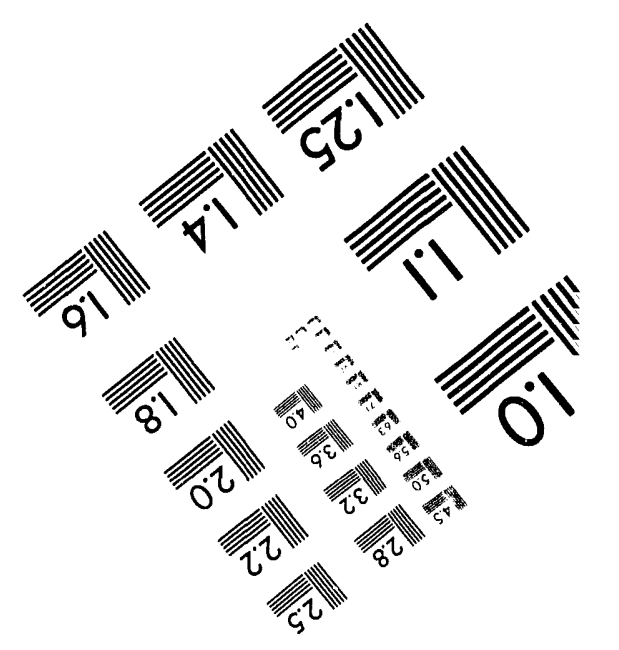



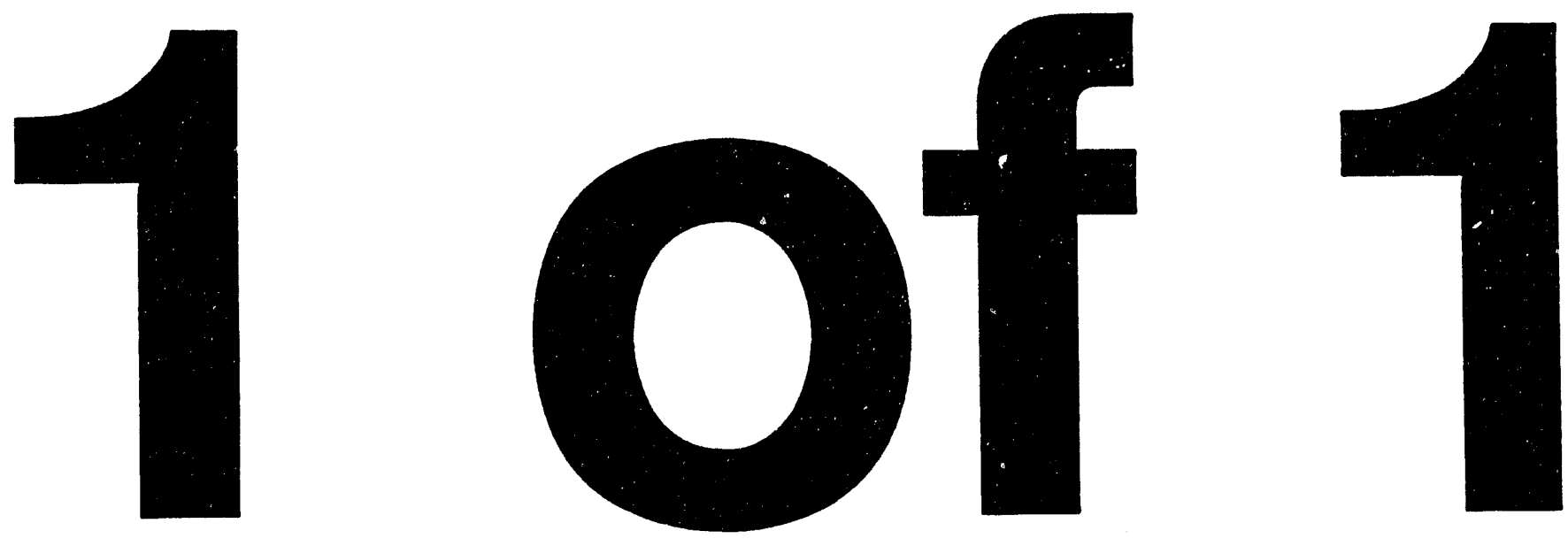
PNL-9968

UC-900

\section{Work Environments and Organizational Effectiveness: A Call for Integration}
J. H. Heerwagen
J. A. Sanchez
J. G. Heubach
J. C. Montgomery
B. W. Brown
W. C. Weimer

July 1994

Prepared for

the U.S. Department of Energy

under Contract DE-AC06-76RLO 1830

Pacific Northwest Laboratory

Richland, Washington 99352

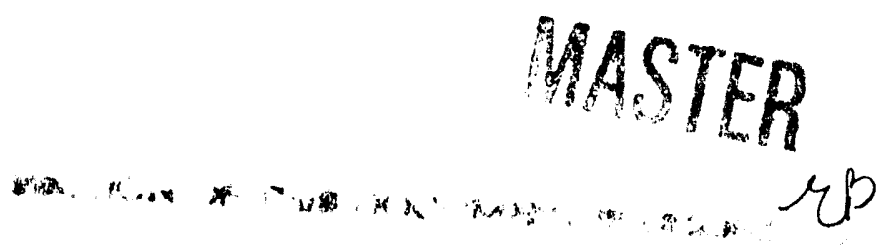




\section{Executive Summary}

In response to a request from the Pacific Northwest Laboratory's Analytical Chemistry Upgrades Program, a team was formed to 1) review work environment and productivity research, 2) report the research in a manner usable to organizational decision-makers, 3) identify Hanford Site facilities examples of the work environment principles and research, and 4) publish the review results in a refereed journal. This report summarizes the work environment-organizational effectiveness research reviewed, provides the foundation for a publishable article, and outlines the integration of work environment research and organizational effectiveness in continuing improvement programs and strategic planning.

The research cited in this review shows that the physical work environment offers a valuable tool that, used wisely, can contribute significantly to the performance of an organization, its bottom-line economics, and the well-being of all of its employees. This finding leads to one central recommendation:

- To derive the maximum benefit to the corporation, managers and designers must integrate organizational goals and programs with work environment design.

The process should be a truly interdisciplinary undertaking with a systems orientation which looks at interconnections between events, procedures, people, and disciplines.

The project had four primary goals: 1) to provide a research basis for integrating organizational planning and programs with work environment planning and design; 2) to convince managers to integrate work environment planring with organizational development and corporate strategy; 3) to convince facilities planners to incorporate organizational culture, corporate strategy, work process, and individual well-being into the facilities planning process, which includes analysis, design, and evaluation; and 4) to highlight Hanford Site facilities planning and design planning processes which apply the principles of work environment-organizational effectiveness research presented in this review.

An extensive review of research and theory from the fields of organizational development, management, environmental psychology, and architecture identified numerous ways in which the physical work environment influences behavior and organizational outcomes. While much of the research cited focuses on office environments, the results and design principles and practices are relevant to a full range of settings: laboratories, schools, hospitals, and factories. The major findings of the research reviewed are summarized below in four areas: 1) performance, 2) well-being, 3) image, and 4) turnover and recruitment. 


\section{Performance}

The designed environment has both direct and indirect effects on individual work performance and organizational effectiveness/ productivity. The environment acts in a direct way by creating conditions that make work easy or difficult. Work stations can create physical strain which results in lost efficiency and time, medical claims, and interrupted communication. Work stations that fit the job tasks like a glove can also be created.

The physical layout of the work process for both manufacturing and office settings significantly impacts productivity. For example, productivity can be increased by designing the work environment to fit work processes, organizational structure (project teams or loosely coupled project networks), and type of work (data analysis, data entry, and laboratory procedures).

\section{Well-Being}

An environment design affects the health and performance of its employees physiologically, socially, and psychologically. Employee health is affected by the design and maintenance of the heating, ventilating, and air conditioning systems; the ergonomics of the work station; and the availability of fitness centers and programs.

Although a great deal of attention has been paid to the direct impacts of environments on health and performance, less is known about the relationship between the environment and the social and psychological processes that mediate performance and health outcomes. However, research from $a$ variety of fields shows that the environment affects health and performance through its effect on psychological processes including motivation, mental stimulation, and attentional efforts; perceived and actual control over the environment (control over room temperature and control over social interaction); privacy; contact with nature; and co-worker interaction.

\section{Image of the Organization}

The image projected by the physical environment not only affects the people working in it, but also the visitors and others whose perceptions of workers are congruent with the visual quality of the environment. People working in pleasant, attractive, and neat environments are perceived by others in a positive light; people working in unpleasant, drab, and untidy environments are commonly perceived in negative terms. To some extent, this image may be why many organizations invest so much money and design effort in their public spaces. Clients and important visitors generally experience only these areas and do not see the back room where most of the day-to-day work occurs. Thus, visitors are filled with the aura of success and power associated with well-appointed lobbies and expensively furnished board rooms. In contrast, employees who pass through an impressively designed lobby to a drab workspace notice the discrepancy in environments and perceive a message communicated by the environment that employees are less valued by the organization than its visitors. 


\section{Turnover and Recruitment}

The loss and retraining of employees result in tremendous costs to an organization. In a number of studies, work environment facilities have been shown to be linked to reduced turnover and improved recruitment, particularly for high-level professionals. For example, some corporations are now going far beyond offering state-of-the-art equipment to recruit top scientists; they offer aesthetically appealing laboratories, quadrupled benchtop work surface, management-size private offices, and multiple small team meeting areas surrounded by beautiful pastoral landscapes. In addition, initial research efforts have shown that office appearance influences people's evaluations of the appeal of potential jobs. 


\section{Contents}

Executive Summary $\ldots \ldots \ldots \ldots \ldots \ldots \ldots \ldots \ldots \ldots \ldots \ldots \ldots$ iii

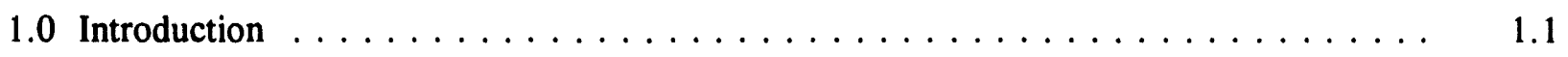

1.1 Conceptual Framework $\ldots \ldots \ldots \ldots \ldots \ldots \ldots \ldots \ldots \ldots \ldots$

1.2 Recent Changes in Organizations and Work Environments . . . . . . . . . 1.2

1.3 Overlooked Investment Opportunities $\ldots \ldots \ldots \ldots \ldots \ldots \ldots \ldots$

2.0 Work Environments and Organizational Effectiveness: What Does

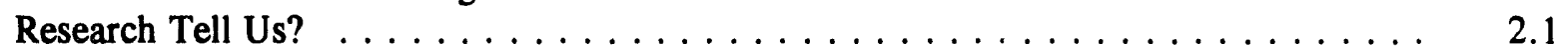

2.1 Productivity and Work Effectiveness $\ldots \ldots \ldots \ldots \ldots \ldots \ldots \ldots \ldots$

2.1.1 Work Process Layout $\ldots \ldots \ldots \ldots \ldots \ldots \ldots \ldots \ldots \ldots$

2.1.2 Contributions of Individual Work Stations $\ldots \ldots \ldots \ldots . \ldots \ldots$

2.1.3 Customizing the Environment to the Task and Person $\ldots \ldots \ldots \ldots$

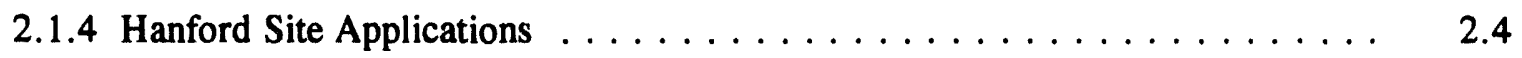

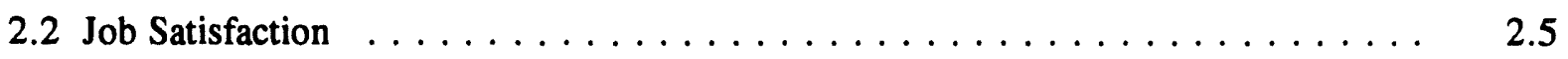

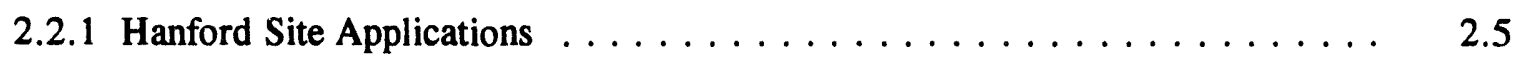

2.3 Cognitive Functioning and Creativity $\ldots \ldots \ldots \ldots \ldots \ldots \ldots \ldots$

2.3.1 Negative Effects on Cognitive Functioning $\ldots \ldots \ldots \ldots$

2.3.2 Positive Effects on Cognitive Functioning $\ldots \ldots \ldots \ldots \ldots$

2.3.3 Hanford Site Applications . . . . . . . . . . . . . . . 2.9

2.4 Team Effectiveness $\ldots \ldots \ldots \ldots \ldots \ldots \ldots \ldots \ldots \ldots \ldots$

2.4 .1 Team Identification $\ldots \ldots \ldots \ldots \ldots \ldots \ldots \ldots \ldots$

2.4 .2 Proximity and Affiliation $\ldots \ldots \ldots \ldots \ldots \ldots \ldots \ldots \ldots$

2.4 .3 Visual Access $\ldots \ldots \ldots \ldots \ldots \ldots \ldots \ldots \ldots \ldots \ldots \ldots$

2.4 .4 Communication $\ldots \ldots \ldots \ldots \ldots \ldots \ldots \ldots \ldots \ldots \ldots \ldots \ldots$

vii 
2.4.5 Relationship of Work Type and Design $\ldots \ldots \ldots \ldots \ldots \ldots \ldots \ldots$

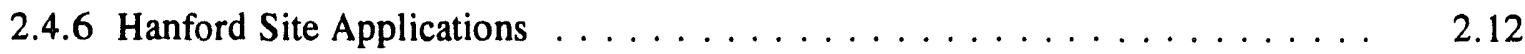

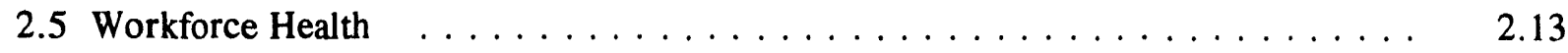

2.5.1 Sick Building Syndrome $\ldots \ldots \ldots \ldots \ldots \ldots \ldots \ldots \ldots \ldots \ldots$

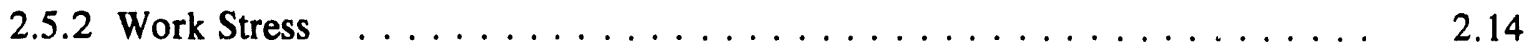

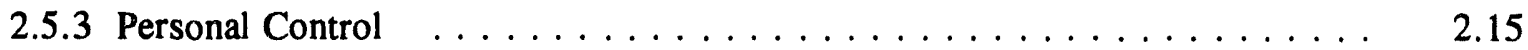

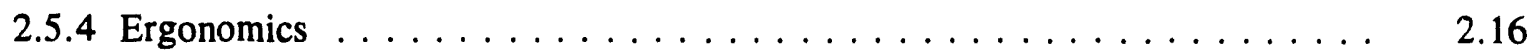

2.5.5 Computers and Health $\ldots \ldots \ldots \ldots \ldots \ldots \ldots \ldots \ldots \ldots$

2.5.6 Health and Wellness Facilities $\ldots \ldots \ldots \ldots \ldots \ldots \ldots \ldots$

2.5.7 Hanford Site Applications $\ldots \ldots \ldots \ldots \ldots \ldots \ldots \ldots \ldots \ldots$

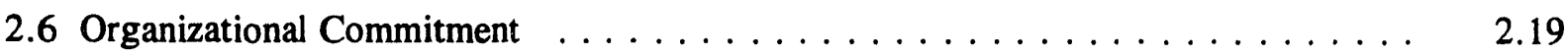

2.6.1 Recruitment and Retention $\ldots \ldots \ldots \ldots \ldots \ldots \ldots \ldots \ldots$

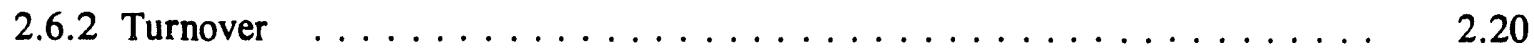

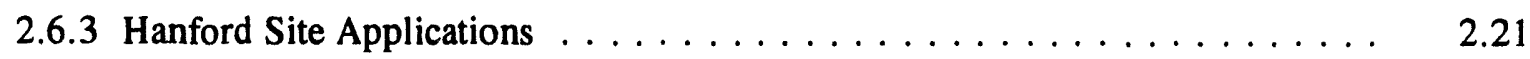

2.7 Organizational Values and the Physical Environment $\ldots \ldots \ldots \ldots \ldots \ldots$

2.7.1 Communicating Organizational Values and Norms $\ldots \ldots \ldots 2.22$

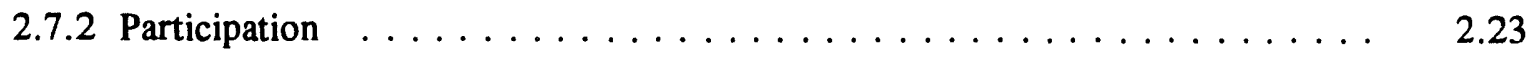

2.7.3 Social Relationships $\ldots \ldots \ldots \ldots \ldots \ldots \ldots \ldots \ldots \ldots \ldots \ldots$

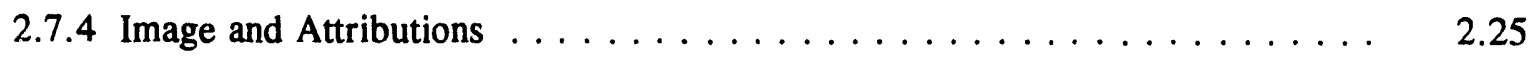

2.7.5 Positive Work Affect and Environmental Pleasantness . . . . . . . . . . 2.26

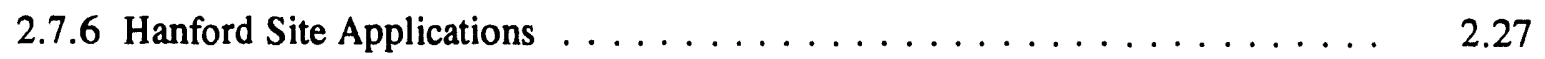

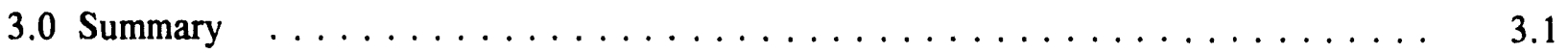

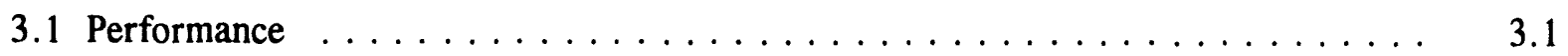

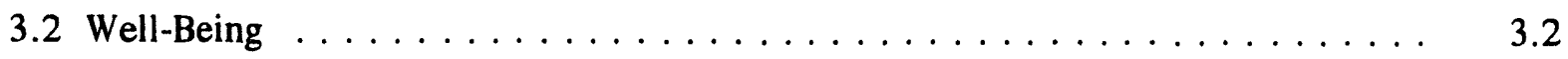




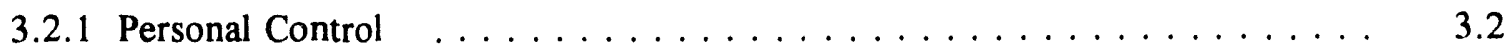

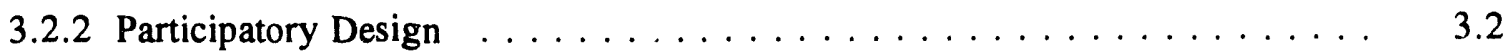

3.2.3 Job Satisfaction, Work Stress, Sensory Stimulation $\ldots \ldots \ldots \ldots \ldots$

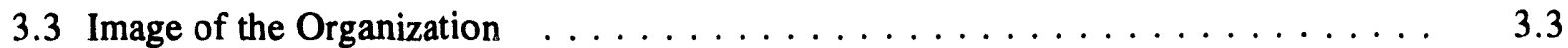

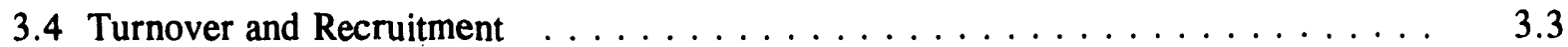

4.0 Recommendation: A Call for Integration $\ldots \ldots \ldots \ldots \ldots \ldots \ldots \ldots \ldots$

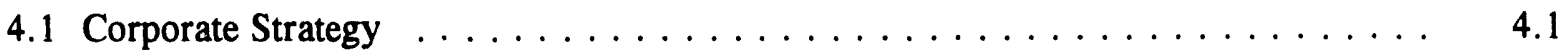

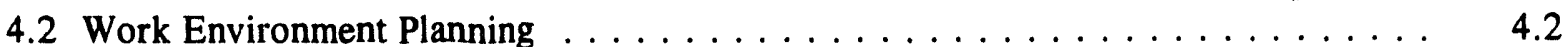

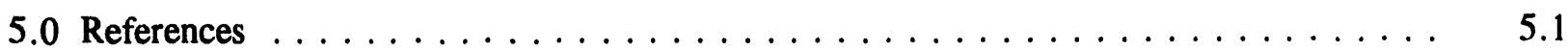




\subsection{Introduction}

The purpose of this report is to show that the physical work environment affects a number of areas critical to an organization's effectiveness. This report brings together research from a variety of fields to show the relationship between an organization's effectiveness and its physical work environment. The report also cites Hanford Site facilities which illustrate work environment research and facilities design principles. The research reported on in this document was performed for the Pacific Northwest Laboratory's (PNL) ${ }^{(\mathbf{a})}$ Analytical Chemistry Upgrades Program, which had requested a literature search for research focused on relationships between work environment and productivity.

The physical work environment carries the potential to improve an organization's effectiveness significantly and, therefore, to contribute to increased competitiveness. All too frequently, the money spent on facilities fails to fully achieve the potential benefits. Organizations spend vast sums of money each year to construct, renovate, and re-configure office buildings, laboratories, schools, hospitals, stores, and manufacturing facilities. The same organizations spend large amounts of money on projects designed to improve organizational effectiveness. Unfortunately, organizational effectiveness programs and facilities projects usually are separate and distinct and thus do not build upon common areas of concern for high-quality performance and work life. A better understanding of the physical work environment is required in order to allow managers and staff to integrate work environment and organization.

In a major study of office workers, pollster Louis Harris (1988) found that managers were well aware of the need to link facilities improvement to their overall organizational plans: 98 percent of those polled said this linkage was "very important." Yet less than a third said such linkages occurred in their own organization. This report bridges the gap between the worlds of facilities planning, work environment research, and organizational effectiveness. It links the physical aspects of work and outcomes of interest to organizational leaders, including work performance and efficiency, motivation, organizational commitment, job satisfaction, health, and team work processes.

\subsection{Conceptual Framework}

Over the past 50 years, researchers and theorists in a number of fields have clarified and ascribed greater importance to the role of the physical environment (see Heubach [1984] and Bell [1978] for reviews of theory in this area). Recent work in defining the physical environment and its interrelationships has focused on models which define the physical environment not merely as a medium, but as a definable variable capable of detailed coordination with one or more socio-behavioral analyses and outcomes. For example, conceptual frameworks appeared in which the environment was defined as a set

(a) Pacific Northwest Laboratory is operated for the U.S. Department of Energy by Battelle Memorial Institute under Contract DE-AC06-76RLO 1830. 
or field of discrete points in space, each with different access to information which influences human behavior (Canter and Kenny 1975; Archea 1984).

The physical environment also appears in theoretical and conceptual frameworks in the fields of organizational and industrial psychology (see Carnevale [1992] for a review). Similar to the work in environmental psychology, architecture, and social psychology, the conceptual role of the physical environment progressed from the role of a neutral shelter (Herzberg et al. 1959) to an active player in influencing "not just production, but social, cultural, and psychological dimensions of work as well" (Carnevale 1992, p. 433).

Despite the theoretical importance environmental psychologists, architectural scholars, and organizational psychologists attach to the physical environment, researchers in environment-behavior fields have yet to frame their work to examine the interactions between the environment and organizational goals. Similarly, researchers in organizational psychology have yet to include the work setting in studies assessing issues of critical importance to organizations--such as performance on diverse kinds of tasks including creative problem solving and other high-level cognitive functions, attachment and loyalty, well-being, absenteeism, and turnover. Nor has attention been paid to the interaction of organizational culture and the physical environment in terms of the values and meanings that are conveyed and played out through the context of work.

This lack of attention to physical features of the work setting has to do, in part, with a widely held belief that the environment can only be an inhibitor of work performance or job satisfaction; it cannot exert positive effects (see Carnevale [1992] and Sundstrom et al. [1986] for reviews of theory in this area). Carnevale, analyzing the lack of attention to the physical environment in organizational theory, cites three key issues: 1) the legacy of human engineering which viewed the environment's support of task instrumentality as the critical factor in work settings, i.e., quality of life issues were regarded as unimportant; 2) standardization of environmental design that ignored individual differences or local values/beliefs; and 3) the belief that the physical environment contributed only to employee dissatisfaction. According to the "hygiene theory" proposed by Herzberg et al. (1959), the environment exerts its effects only when it produces conditions that make work difficult (e.g., it is too hot, cold, noisy, crowded). Negative conditions at work were not seen as part of a continuum, with the opposite end being positive conditions that enhance motivation and work performance. The ability to influence motivation and work performance was viewed as resulting from organizational policies and procedures.

\subsection{Recent Changes in Organizations and Work Environments}

In recent years, organizations have been forced to adjust to changing technological, social and economic climates (Offerman and Gowing 1990). These pressures demand new ways of working and new environments in which to carry out these changes to remain competitive in a worldwide market.

A number of corporations have begun to experiment with new work environments that reflect these changes in organizational structure, including the "virtual organization" in which work is carried out 
independent of place; the "electronic cottage" and telecommuting from home (Toffler 1981); the nonterritorial office in which workers do not have their own workspace, but rather move around the building in accordance with their activities (Allen and Gerthsberger 1973); and "activity centers" which combine features of the nonterritorial office with opportunities for privacy in an enclosed space (Stone and Luchetti 1985).

At the heart of the interest in new work settings are two major concerns: productivity and employee well-being. These concerns have emerged simultaneously among environmental psychologists (Stokols 1990; Steele 1986; Brill et al. 1984, 1985; Becker 1990) and organizational/industrial psychologists (Schein 1990; James and James 1989; Carnevale 1992; Levinson 1988). Designers, responding to these new challenges, have sought ways to use the environment as a means for enhancing the quality of work performance (Brill 1984, 1985) and as a context for creating and expressing human values and other outcomes associated with well-being, such as positive affect, self-esteem, and a sense of belonging (Steele 1973; Goodrich 1982; Stokols 1992).

Many of these new work environments are based on fads and the feeling that "something" must be done. Very little effort has been made to apply research on human behavior, well-being, and work performance as it relates to the physical environment. Nor have there been sufficient attempts to evaluate these new settings to see what works well and what does not and why. The lack of evaluation is endemic in the design professions for several reasons: 1) the evaluation process is not built into the fee structure of building design; 2) once a building is finished, the architect considers his/her work to be compleie and moves on to a new task; and 3) neither the designer nor the client seems to have an interest in learning from potential mistakes--it is almost as if mistakes are better left undiscovered because, once in the open, they will need to be resolved. Design flaws can prove to be very costly to an organization. This situation makes it all the more important to do a building right in the first place. Doing it right means heeding and integrating the research that has already been done on person-environment relationships in work settings.

\subsection{Overlooked Investment Opportunities}

One common impediment to doing it right in the first place is the staggering size of the initial capital expenditure for a new facility or for a major renovation. All too often long-term or life-cycle benefits are ignored in favor of short-term savings, i.e., design features which could enhance productivity and organizational well-being are sacrificed in face of the initial building costs. A life-cycle cost approach reveals the imbalance in building costs versus labor and benefits over the lifetime of a building or renovation. The investment in buildings, whose up-front costs can seem staggering, pales in comparison with the life-cycle costs of salaries and benefits. Therefore, any improvement in the physical environment will contribute significantly to the long-term economic benefits of a new or renovated facility.

Investment costs can be divided into costs associated with the building and furnishings and costs associated with people. Moleski and Lang (1982) argue that problems of human development and 
satisfaction in work settings become critical when viewed in terms of life-cycle costs. They note that the salaries and benefits to staff consume over 90 percent of the money spent, compared with 2 percent for the building systems and 7 percent for upkeep and maintenance. Of controllable costs, workers account for 50 percent; however, in labor-intensive service and government agencies, workers account for 70-80 percent of all costs (Freidman 1991). In addition, significant hidden costs accrue from staff learning their jobs, i.e., "coming up to speed." In light of these figures, Moleski and Lang note: "The inconspicuous cost of a building not conforming to the human values of the user is much greater than the conspicuous costs of the building construction" (1982, p. 329).

The following examples provide a sense of the scope of the investment in construction and renovation of facilities. In a recent study of the facilities needs of the nation's aging federal laboratories, the U.S. General Accounting Office (GAO) found that 54 percent of the laboratory space is over 30 years old. The GAO further reported that the state of the laboratories has reduced scientific productivity. In addition, federal agencies cited inadequate facilities maintenance and facilities which fail to meet current health and safety standards. The cost of renovating laboratories is massive; however, the costs of failing to renovate the nation's laboratories and constructing new facilities will detract from the agencies' ability to meet their expanding research mission and the researchers' need to perform advanced R\&D.

Congress is funding major projects to modernize existing laboratory facilities and construct new ones to perform advanced R\&D. For example, in fiscal year (FY) 1993, Congress appropriated $\$ 70$ million of $\$ 205$ million requested to modernize the Agricultural Research Service's (ARS) Beltsville laboratory. The Beltsville laboratory, however, is only one of the 220 government-owned laboratories operated by eight federal agencies.

Costs of new construction planned to increase performance and safety are considerably more expensive. For example, a proposed new $\$ 1.6$ billion National Institutes of Health (NIH) clinical center will provide facilities "essential for fulfilling NIH's mission" (GAO 1993, p. 5). The U.S. Army Corps of Engineers validated NIH's claim that the existing 38-year-old facilities greatly constrained the Institute's ability to perform.

Within PNL alone, construction projects (funded by Battelle and the U. S. Department of Energy) amounted to $\$ 50$ million in FY 1993. The FY 1993 funds include capital construction (i.e., modifications, additions, alterations to existing facilities, and/or new construction). Of the total amount authorized, approximately $\$ 4$ million per year is associated with alterations and modifications (e.g., new roofs, renovations to meet new code and government regulations, and changes to extend the life of existing facilities). Of this yearly allocation, approximately 90 percent is spent on addressing health and safety issues: The remaining 10 percent is associated with improving the quality of the workplace (e.g., lighting, moving doors for access).

In contrast to the $\$ 50$ million expended on facilities, PNL spent just over $\$ 180.8$ million in salaries for FY 1993. PNL's largest cost is its employees. Any increment in the productivity of this costly 


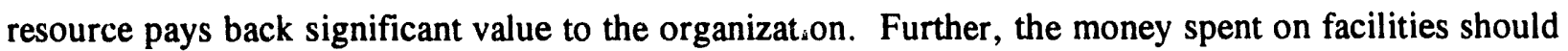
be used to design spaces which promote increased performance.

Given these multi-million dollar budgets for construction and renovation and the vast sums spent on salaries and benefits, it is essential that buildings be well-designed from the start. This factor means paying attention to factors that sustain productivity at work and support human well-being. Research in environment-behavior, organizational psychology, and management sciences offers information critical to creating a stronger integration between work environments and organizational effectiveness.

This report is organized in four sections. Section 1.0 introduces conceptual frameworks which relate the physical environment and organizational goals and briefly describes recent changes in organizations and work environments. Section 2.0 summarizes research which shows different ways in which work environments affect organizational effectiveness (i.e., productivity and employee well-being). Section 3.0 summarizes the research results. Section 4.0 calls for the integration of work environment planning and design with strategic organizational planning and continuous improvement programs. It describes integrated organization-environment strategic planning, organizational-environmental development, and integrated faciiities-organization planning and design approaches that can be used to promote organizational effectiveness and employee well-being.

For each major subsection of the research cited in Section 2.0, examples of facilities at the Hanford Site are presented to show applications of the design principles related to the research discussed. 'The examples are drawn from the following facilities at Hanford: the Analytical Chemistry Laboratory's (ACL) office spaces and laboratories at PNL, the proposed Hanford Site Entry Control Center (Entry Center), PNL's Energy and Environmental Sciences Building (EESB), and the Department of Energy, Richland Operations Office (DOE-RL) day care center. 


\subsection{Work Environments and Organizational Effectiveness: What Does Research Tell Us?}

The following sections present organizational research and work environment research to provide an integrated view of the relationship between the context of work and valued organizational outcomes, including productivity, job satisfaction, cognitive functioning and creativity, team effectiveness, health, and employee commitment to the corporation. These outcomes are important whether the work setting is an office, retail business, or microbiology laboratory.

\subsection{Productivity and Work Effectiveness}

The design of the physical arrangement of the workplace can have an extraordinary impact on productivity, communications, and the workers themselves. A number of environmental factors influence productivity. These factors include work process layout, individual work station features, and environments customized to fit the task and person. Each factor is described separately below.

\subsubsection{Work Process Layout}

Benefits of effective design accrue to an organization in terms of increased production, cost reduction, reduction in number of employees needed, and improved quality. Benefits also accrue to the employee in terms of improved job satisfaction, enriched work, and improved career paths and pay structures. Redesign of the work layout is seen as the first step in improving production and organizational performance (Black 1991).

Benefits from workflow layout are most obvious in the case of manufacturing, where work and material flow clearly from one point to the next until a product emerges. However, as Davenport (1993) indicates, any organization can be conceptualized in terms of inputs, work or process flows, and outputs since any organization or sub-unit converts some form of input (e.g., parts, information, service orders) into some type of output (goods, services, information).

Time spent on tasks can be reduced by evaluating the layout of the space and designing the space based on four design principles: frequency of use, functional grouping, importance, and sequence of use (Fowler et al. 1968). Evaluating the workspace layout will assist in using the area more effectively.

A number of organizations have documented the benefits of an appropriate work flow design. For example, in an administrative organization studied by Feather and Cross (1988) redesigning the work layout reduced cycle time (total time needed to complete each document) by 60 percent, reduced backlog by 80 percent, and tripled output of critical documents. Similarly, Hallmark Inc. reorganized the way new cards were designed, grouping together people from a variety of disciplines who formerly had been separnted by organizational barriers. People were purposely placed to allow simple handoffs for 
the roughly 25 steps involved in the design and production process. Under this arrangement, cards that had formerly taken 2 years or more to go from concept to production were completed 8 months ahead of schedule (Champy and Hammer 1993).

In terms of space requirements, Schonberger (1982) found that, by using a product-oriented work design, a Japanese firm was able to dramatically reduce the amount of floor space and cost of a manufacturing plant (300,000 square feet at a cost of $\$ 100$ million). An American company using the same amount of machinery and manufacturing the same product needed 900,000 square feet of floor space at a cost of $\$ 300$ million.

Finally, in a highly publicized example, the Chrysler Corporation committed almost $\$ 1$ billion to design and build its new R\&D facility in Auburn Hills, Michigan. One of the primary goals of the new facility was to reduce design and production time for a new car from 5 years to 3 years. Chrysler engaged in a holistic development approach which included concurrent engineering, marketing, facilities design, purchasing and finance re-design, and employee participatory design and development. Chrysler achieved its goal. The production time for Chrysler's new car, the Neon, was reduced to 3 years at a cost of $\$ 1.3$ billion, compared with Ford's 5-year development of the new Escort at a cost of $\$ 2$ billion and GM's 7-year development of the Saturn at a cost of $\$ 5$ billion (Woodruff and Miller 1993).

A few key features of the building design contributed directly to the efficiency gains: reduced distance between department and project groups (travel time between departments was reduced from a maximum of 45 minutes at the previous facility to a maximum of 5 minutes at the new facility); reduced distance within each production team (car production teams were organized vertically from floor to floor for improved efficiency); team cohesiveness built through functional-spatial proximity; and the full range of development, testing, and management facilities collocated at one site.

\subsubsection{Contributions of Individual Work Stations}

Concern with the productivity outcomes of office work settings is exemplified in the large scale studies produced by the Buffalo Organization for Social and Technological Innovation (BOSTI) in the 1980s. The BOSTI work focused on identifying factors in the office environment that contribute to work performance and job satisfaction (Brill et al. 1984, 1985). In the two-volume report generated from survey studies of $\mathbf{5 0 0 0}$ office workers, including managers, professionals, and clerical workers, the BOSTI team identified two factors which significantly influenced job performance: 1) the amount of enclosure in the workspace (the greater the enclosure, the higher the performance), and 2) the overall spatial layout of the workspace.

The layout features associated with increased job performance were 1) having a single entrance to the work station; 2) not having one staff member seated at work directly in front of another; 3) not 
having open sides, especially on an aisle; 4) having some open space; 5) having at least two work surfaces; and 6) for managers, having a work surface that permits face-to-face, across-the-desk interactions. Winer (1989) identified common misuses of workspace which he contends affect productivity outcomes. Common individual workstation misuses include improper use of office furniture, inadequately planned storage and work areas, and individual workstations sacrificed in favor of high-profile work areas (e.g., a high-image lobby backed by suboptimal offices/workspaces).

\subsubsection{Customizing the Environment to the Task and Person}

In addition to the growing concern with team work, many organizations and designers are looking at ways to increase the "fit" between individual workers and their workspaces or between the type of task and the setting characteristics. Carnevale (1992) notes: "In the final analysis, the optimal or appropriate arrangement of physical setting factors depends on the nature of the task and the work style of the users. These contingencies mean that different types of work activities both demand and depend on varying environmental supports" (p. 430).

Several recent studies on customizing the environment are worthy of attention, even though there is little research on the organizational benefits of customizing the environment. One large multi-national company funded a study of environmental layout and furniture to investigate which combination would best support "operational efficiency and provide optimum comfort conditions" (Tong and Ellis 1986, p. 188). An activity analysis showed that employees have different needs that can be grouped by type of work activity and that should be reflected in the layout and features of the physical working environment. For example, results showed that "desk-based interactors" (nonmanagerial high-grade professionals like PNL's R\&D staff) should be provided small group meeting space in their office or nearby to support the constant gathering together to work on projects.

Another approach introduced by Herman Miller is attempting to create a better match between the individual and his/her workspace by assessing personality variables. This process uses a computer program developed by Schlossberg (A Guide to the Negotiable Environment) to "allow the user to 'negotiate' with the work environment in order to establish surroundings that are in sync with his or her psychological nature" (Gorman 1992, p. 52). The program combines information from the personality test and the individual's work process to configure an "ideal" workspace. The spaces are somewhat limited in their configuration, but the concept is a good example of what matching a process with the individual person or task might consist of.

The idea of individual fit has also received attention from researchers studying ambient conditions. A major difficulty with the design and operation of ambient systems for light, temperature, and air flow is that individuals vary considerably in their preferred environmental conditions. For instance, in a study of lighting preferences, Heerwagen (1990) found that people who have Seasonal Affective Disorder (SAD) preferred significantly brighter task and ambient light in their work environments than did a matched control group who did not experience seasonal changes in mood and energy levels. In a study of high-rise office buildings, Schiller et al. (1988) found that, at any given time, half the workers wanted the environment to be warmer or cooler. This variability has led to the development of the 
Advanced Comfort Systems workstation in which the worker can adjust the temperature, lighting, noise level (using a background noise adjustment), and air flow .

In contrast to fitting the environment to a stationary worker, work environment designers are exploring novel concepts such as "activity centers" and "nonterritorial offices" where workers move about during the day as they switch tasks or if they merely prefer to be in different conditions. Allen and Gerthsberger's study of the nonterritorial office (1973) found that workers did not spend much time in any particular place; rather, they used the environment in a way that was consistent with their tasks. When doing laboratory team work, they occupied work tables near the labs. When writing reports or engaged in analytical work, they sat alone, often at a table near a window.

\subsubsection{Hanford Site Applications}

\section{Entry Center}

The Hanford Site Entry Control Center (Entry Center) is designed along a quasi-activity center approach. The Entry Center will provide "one-stop shopping" for people needing access to the outer areas of the Hanford Site, badging, dosimetry, clearance processing, orientation training, etc. The Entry Center specification calls for private offices for individual work requiring privacy and concentration; shared, centrally located badging, dosimetry and orientation counters for direct customer service activities; and small team meeting rooms for group work.

The primary areas of the Entry Center are an open public area containing service counters, a private office work environment, and a secured file area. The layout ensures easy movement between the open public area where staff serve customers and the private office area where employees perform the work required to support the Site access functions.

\section{PNL's Analytical Chemistry Laboratory (ACL) Mezzanine Offices}

Major changes in the spatial layout and work flow were also a component of the renovation of the mezzanine of PNL's ACL located in the 325 Building. The work process was analyzed to improve the flow of tracking the samples received for chemical analysis. The design of the mezzanine established areas for performing particular tasks and created a smooth flow from station to station. Overall, the required travel distance between tasks was reduced considerably. The analysis allowed for traffic flow and provided appropriate storage to clean up work areas, yielding additional working surfaces and at least doubling the number of people that could work in the workspace. As one worker commented, "In the administrative office, [the renovation] has helped having everything centralized. To my way of thinking, it has made us a more productive team. It has given us an identity. It's great!"

\section{PNL's ACL Laboratories}

Work flow layout is also being used to guide laboratory design as part of an effort to increase productivity within PNL's Analytical Chemistry Upgrades Program funded by the U.S. Department of 
Energy. Four specific goals were identified for PNL's Sample Receiving, Preparation, and Storage (SRPS) Laboratory in the 325 Building: 1) increased ifficiency of sample receiving and preparation; 2) increased sample throughput while maintaining safety; 3) total accountability for samples in receiving, preparation, storage, and return; and 4) clarity for clients in sample delivery, sample analysis, and return.

Before design and renovation, there was no centralized sample delivery point, there were multiple sample storage locations, and employees performed related tasks in separate laboratories. The design of the 325 Building SRPS Laboratory centralized sample delivery and consolidated nonradiation and radiation zone operations, thereby reducing time and money spent for radiation surveys required in crossing between zones; providing an administrative work zone; creating centralized reserve storage; simplifying laboratory traffic patterns; and grouping related functional operations. While it is too early to assess performance because the laboratory became operational in April 1994, the laboratory design demonstrates the results that can achieved through work process and work environment analysis.

\subsection{Job Satisfaction}

Job satisfaction is a critical variable in most organizational development theories. It is regarded as an important contributor to work performance and organizational attachment. Further, employees who are more satisfied with their jobs also experience fewer health problems (Sales and House 1969, cited in Klitzman and Stellman 1989).

Although relatively few studies of the physical environment have included measures of job satisfaction, researchers have found that environmental conditions contribute significantly to job satisfaction outcomes. Factors found to be associated with job satisfaction include air quality, temperature, lighting, privacy, pleasantness of the environment, and social relationships (Klitzman and Stellman 1989; Sanoff 1986). Perceptions of poor air quality and temperature, too much or too little light, lack of privacy, and negative social interactions are associated with lower levels of job satisfaction, while positive social relations and privacy are associated with higher job satisfaction.

\subsubsection{Hanford Site Applications}

\section{PNL's ACL Mezzanine Offices}

Dramatic changes in job satisfaction can correspond to changes in the work environment. Before renovation, the 325 Building mezzanine (no windows, low ceiling, noisy) was described by employees as ". . a typical Hanford root cellar"; ". . . archaic, even when compared to the back room of a larger grocery store"; and ". . . an embarrassing office space for some of Battelle's most highly visible projects." 
An interdisciplinary team involved employees in analyzing processes, defining goals and objectives, and reviewing and recommending designs for the mezzanine. In addition to work flow and spatial layout, the team considered the full range of design issues, including ergonomics, safety and health, psychosocial variables, and aesthetics. Significant changes in functional layout, aesthetics, and the heating, ventilating and air-conditioning (HVAC) system, together with increased office and work station enclosure, led to occupants and visitors describing the office setting quite differently: "A feeling of pride--one of belonging--a team spirit!"; ". . . a more professional attitude"; and "it has . . . given us an identity" and ". . made us a more productive team."

\subsection{Cognitive Functioning and Creativity}

The workplace can enhance or inhibit cognitive processes. Higher cognitive functioning and creativity require not only the absence of distractions, but may also depend on the p:esence of particular kinds of workplace features. Given that much of the work currently performed is knowledge-based and involves thinking, planning, analysis, and data manipulation, the relationship between the environment and cognitive functioning should receive greater research attention.

The limited environment-behavior and educational research that has been performed indicates that negative outcomes are likely when the worker's attention is frequently interrupted (such as by noise or visual distractions), when conditions in the environment make it difficult to process needed information (e.g., inappropriate lighting, glare on the computer screen, temperatures that are too cold or too hot), or when the environment is boring. Much less obvious is the way in which the environment may act to influence cognitive functioning in a positive way by providing settings conducive to creative problem solving, planning, thinking, or joint collaboration.

\subsubsection{Negative Effects on Cognitive Functioning}

Distractions, especially from voice intrusions, are particularly detrimental to tasks requiring focused attention such as high-level cognitive activities (e.g., planning, thinking, reading difficult materials, and writing) that require analysis and synthesis. Human voices are distracting because they convey highly salient information that is difficult to tune out. Other tasks in which focused attention would be impaired by distractions from human voices or interruptions include those requiring close attention to detail, such as proofreading, entering data, and following precise laboratory procedures.

Numerous office evaluations have found high levels of distraction associated with frequent interruptions and people talking or moving around the environment (Marans and Sprecklemeyer 1982; Sundstrom et al. 1986; Heerwagen et al. 1990; Wineman 1982). To a great extent, these problems are exacerbated in open plan offices and by the widespread use of paneled cubicles. Such arrangements do not provide sufficient enclosure or sound absorption, thus making it much easier to be distracted by neighbors' conversations as well as conversations from people who are walking nearby. In addition to making it difficult to work, distractions generate negative feelings, including irritability and annoyance that may spill over into the interpersonal realm, making teamwork and collaboration difficult. 
In an office evaluation study which plotted environmental ratings on floor plans, Heerwagen ${ }^{(a)}$ also found that occupants of private offices located on major circulation paths reported high levels of distraction. Organizational norms supporting an "open door" policy appear to have been associated with higher levels of distraction in this instance.

\subsubsection{Positive Effects on Cognitive Functioning}

Given the premium value on creativity and cognitive functioning, it is worth asking also how the physical environment can have positive effects; i.e., can it help promote high-level cognitive activities, including creativity and innovation that are essential to organizational effectiveness?

Creative activity does not occur readily in a high-stress environment. A stressed mind tends to be narrowly focused, compared with creative meta-activity (which is associated with expansive ideation and access to latent memories, thoughts, sensations, and analogies that normally lie out of reach). Thus, one of the essential environmental requirements for high-payoff behaviors is reduction in stressful stimuli (e.g., noise, distractions, interruptions).

Althougiı no direct evidence is available on this topic, there is reason to believe that the environment can serve as a catalyst for creative activities. Evidence for this claim comes from several areas: 1) the impact of environmental stimulation, 2) the impact of the environment on positive affect, 3) the impact of the relationship between positive affect and cognition, and 4) the impact of spontaneous encounters with other people who can help develop creative ideas.

Research by Isen and her associates indicates a link between positive affect and creative problem solving (Isen et al. 1985, 1987). In their studies, positive affect was induced experimentally, usually with a small gift or praise, or by viewing funny movies. Positive affect has also been manipulated in other studies by varying environmental stimuli. Environmental features associated with positive affect states include contact with nature (Ulrich et al. 1991; Ulrich 1993); visually attractive and pleasing places, especially those with interesting decor, posters, plants, or fish tanks (Katcher et al. 1983; Campbell 1979); soft surfaces and comfortable places to sit (Sommer and Olsen 1980); the presence of sunlight in a room (Boubekri et al. 1991); and moderate levels of stimulation and sensory variability (Platt 1961). High degrees of control over the environment and one's own behavior (e.g., being able to move around freely) are also associated with positive experience (Holahan 1976).

\section{Role of Environmental Stimulation}

Reduction in environmentally induced stress is not, in itself, sufficient to provide conditions conducive to creativity and other higher level cognitive activities. An environment devoid of stimulation can lead to boredom and passivity (Cooper 1968), just as an environment that is too stimulating can lead to stress and disorganized activity. Environmental features that are somewhat stimulating without

(a) Heerwagen, J. Unpublished report. 
being stressful are more likely to be associated with optimal cognitive functioning. Such features include moderate levels of environmental complexity and sensory variability.

Schooler (1984) argues that environmental complexity is associated with intellectual flexibility and more self-directed orientation. Cooper (1968) notes that complexity includes the social environment and behavioral variability as well: "social contacts and freedom to move away from the work bench can also serve as sources of varied stimulation" (p. 40). He further contends that monotonous conditions lead people to seek out cognitive novelty such as through daydreaming and fantasy. He cites studies that show lower scores on tests of novelty production in groups that have been exposed to monotonous conditions as compared with more varied stimulation. Furthermore, restricted sensory stimulation appears to have a more negative effect on complicated intellectual tasks than on easy and routine tasks, according to Cooper's report.

Features that show change and variability across time may be especially desirable in windowless workspaces where contact with real changes in daylight and season are not possible. Windowless spaces are frequently associated with feelings of depression and claustrophobia (Ruys 1970) and negative affect. In a study comparing the use of visual decor in windowed and windowless offices, Heerwagen and Orians (1984) tested the hypothesis that people in windowless offices would embellish their spaces with more visual materials to compensate for the sensory deprivation of the environment. They found that people in windowless offices used almost twice as many posters and paintings and that the visual materials were predominantly of landscapes, flowers, and small animals. The posters and paintings were frequently positioned in the occupant's primary view field. A number of people commented that they glanced at the posters frequently because it made them feel good. Similar results are reported by Scheiberg (1990).

Research also suggests that features of natural environments can be simulated effectively. For instance, Young and Berry (1979) found that an artificial window and nature sounds were as effective as a real window in producing positive responses in an experimental setting. Researchers at Stanford Medical School developed an artificial window, complete with backlighted films of outdoor settings and a lighting system that synchronizes with actual daylight conditions to produce changes in lighting intensity from sunrise to sunset. The window was developed to combat disorientation and other psychological problems generated in windowless intensive care units (Keep et al. 1980).

All too often, design elements which create environmental complexity are perceived as frills that are a misuse of government money. In fact, these very features likely contribute to increased productivity, creativity, organizational loyalty, and decreased work-related stress.

\section{Role of Spontaneous Encounters}

Spontaneous social encounters can stimulate creativity and innovation. Environmental design and organizational processes can increase the likelihood of such encounters by deliberately providing interaction spaces and by encouraging workers to move around the environment. For instance, "activity centers" and nonterritorial offices are being used in some organizations to replace individual work 
stations (Stone and Luchetti 1985; Allen and Gersthberger 1973). Movement around the office encourages participating in ad hoc groups and also increases the likelihood of spontaneous encounters. These encounters may be especially productive if the environment provides nooks and other small spaces for people to talk for short periods of time without distracting others. Visual access to others can stimulate mental associations which provide opport. aities for what de Bono (1970) calls random stimulation. De Bono describes random stimulation as a tool which can be used purposely to enable creativity.

A study by Allen (1983) compared interactions between engineers in an existing facility with their interactions in a new building specifically designed to promote increased communication through spontaneous encounters. The building used interior glazing to enable people to see one another readily, yet provided acoustical enclosure for concentration. It also provided small break rooms with counters, stools and blackboards for brief meetings. Allen's research revealed that the interactions among staff engineers increased significantly after the move to the new building.

\subsubsection{Hanford Site Applications}

\section{PNL's ACL Mezzanine Offices}

At PNL, the mezzanine of the 325 Building provides an excellent example of how design can effectively combat sensory deprivation and increase the complexity of stimuli. The mezzanine exists in an underground, windowless space located in a 40-year-old government building. Before renovation, the work environment was described as one of the worst office spaces at Hanford--a monochromatic beige environment. The renovated mezzanine includes a glass block wall with backlighting in varied colors that creates a visually interesting, patterned change. In addition, plants provide indoor contact with nature. The uesign also provides variable textures and changes in brightness of lighting as one moves through the space. The use of glass throughout the space also increases the complexity and variability of viewing distances.

The mezzanine of the 325 Building also provides an excellent example of the relationship between design and positive feelings. A new, attractive lunch room was created for staff, along with comfortable, visually appealing conference rooms that are now used for meetings by outside groups. The renovation also provided the staff with more control over their workspaces and clearly distinguished between public and private areas in the central shared workroom. The soft colors and use of rounded surfaces give the feeling of warmth and welcome in a type of environment (e.g., underground) that is often associated with unpleasant sensations. The use of interior windows also provides more distant views that may provide visual relief, and perhaps cognitive tranquility, that might not be present in a small, enclosed windowless office.

\section{Energy and Environmental Sciences Building (EESB) Offices}

Recently constructed PNL office buildings specify windows for a maximum number of staff as seen in the interior courtyards of the Energy and Environmental Sciences Building (EESB) and Information Sciences Building I and II (ISBs). These windows offer contact with nature, increased sensory 
variability, complexity, and cognitive relief. The benefits of reduced distraction for higher cognitive functioning are compromised, however, as staff are doubled-up in offices.

At PNL, both the mezzanine in the 325 Building and the EESB provide ample opportunities for spontaneous encounters by increasing visual contact among staff. Interior glazing and, at EESB, open interior courtyards, enable staff to see one another from a distance.

\subsection{Team Effectiveness}

While most attention to group work outcomes has focused on elements like job design and intergroup communications, the physical setting should be considered as a powerful element in group work design (Sundstrom 1990). Organizations are increasingly using a team approach to work. In some cases, the teams are relatively permanent. In other cases, the members frequently recombine in new groups. Significant workplace questions regarding team effectiveness include how frequently teams change members, whether or not it is desirable to have teams differentiated from one another, and how much interaction and communication are desirable both between and within teams.

\subsubsection{Team Identification}

If it is desirable to have well-identified teams that are relatively stable, the organization should provide an environment that reinforces the feeling of team unity. The feeling of "teamness" is enhanced by the extent to which each team office cluster is differentiated from others in terms of its appearance, furniture, color and other design features (Sundstrom et al. 1990).

\subsubsection{Proximity and Affiliation}

A long history of research has shown that proximity stimulates affiliation and interaction (Festinger et al. 1950; Hall 1966; Altman 1975; Russel and Mehrabian 1978; Beer and Darkenwald 1989). Increased staff friendship/affiliation may benefit organizations through shared ideas, shared responsibilities, mentoring, and problem resolution. Workplace neighbors are more likely to interact with each other and form friendships than are employees who are separated; i.e., the less the objective physical distance, the greater the affiliation and degree of interaction (Gullahorn 1952). Affiliation is also affected by the functional physical distance, which affects the likelihood of individuals coming into contact with each other (e.g., at an elevator, stairwell, or mail slot).

The belief in the power of proximity to influence behavior can be seen in one company's decision to collocate its subsidiaries' chief executives in the new corporate headquarters to improve intersubsidiary working relations (Seiler 1984). To ensure the frequent presence of the subsidiary executives at corporate headquarters, management also budgeted for a small fleet of helicopters and landing pads. 


\subsubsection{Visual Access}

More recent research shows that functional visual fields also affect affiliative behavior (Archea 1984, 1974; Benedikt 1979). Functional visual fields can be quantified by the amount and type of space visible from any point (visual access) and the amount and type of space from which a point is visible (visual exposure). The interaction between these two variables contributes to feelings of privacy and unwanted exposure. Even preschool children understand the subtleties of the behavioral implications of locations in visual space (Heubach 1984). Archea (1977) found that elderly residents of a geriatric hospital adjusted their movement through a building and their occupation of specific spaces in a highly correlated relationship with the characteristics of the visual environment. Frequent views of others may affect affiliation and encourage interaction in common spaces such as in hallways or near shared services. Frequent face-to-face contact influences the formation of social groups, channels of communication for information, and standards for attitudes and behavior in large communities (O'Mara 1989). Greater contact between manager, subordinates and co-workers is a way of fostering innovation and employee satisfaction.

However, visual access must be balanced with needs for privacy and concentration. Numerous studies of open offices show that while workers like the extensive visual field, they find the openness to be noisy and distracting. Further, they do not like being "on view" all the time. Thus, attention needs to be given to providing people with good visual access, while minimizing the feelings of exposure. This balance can be achieved by strategic placement of screening materials, the location and amount of interior/exterior glazing used in a space, and the placenent of workspaces relative to the view potentials.

\subsubsection{Communication}

The design of the work environment either enhances or restricts communication. Allen and Fustfeld (1975), in a project designed to enhance team communication, identified several specific factors associated with increased communications: clustering team areas and separating them from other teams, locating individual offices close together within the cluster, and locating the team leader's office in the center of the cluster. Tong and Ellis (1986) also suggest that group interactions are facilitated by the ready availability of team meeting rooms with appropriate equipment (e.g., display space, writing boards, computer terminals, phones, tables and comfortable chairs).

Team members must also communicate with other teams and individuals within an organization. In the Allen and Fustfeld study, communications and contact with other members of the organization were significantly enhanced by the central placement of a lunch room with a coffee nook (with team office clusters located around the lunch room). Other widely used facilities, such as the copy room and computer room, were also centrally located with equal access from all team areas. 


\subsubsection{Relationship of Work Type and Design}

The degree to which work group clusters are separated from one another and the permeability of their boundaries are related to the type of work the groups do. For instance, Sundstrom (1990) notes that sensitive operations or problem-solving sessions require privacy and concentration and thus need greater enclosure, fewer entry points, and more separation from other groups. Teams in which membership changes or size varies depending upon the particular project require spaces with more permeable boundaries (e.g., more entry points, greater openness into other areas), as well as more meeting areas of different sizes to accommodate spontaneous and planned meetings. In numerous organizations, workers are cross-trained to do many different kinds of tasks rather than specializing in one. Cross-training alleviates boredom, allows everyone to sense the entire work process, and makes it easier to function when one member is not able to perform his/her duties because of injury or illness. Cross-training creates greater movement between work stations and a greater mixing of workers than would be true of more permanent work groups.

\subsubsection{Hanford Site Applications}

\section{Entry Center}

The specification for the DOE's Hanford Site Entry Control Center defines the office work environment according to the type of work groups and type of work conducted. Workers are expected to be cross-trained and will thus move between work stations over the course of the day or week. Small private offices (100 square feet) arranged in clusters will allow for concentrated work. The clusters, which also include team open space and meeting rooms, will promote intergroup contact. Because spatial proximity fosters increased affiliation and interaction, the design should increase idea sharing, social cohesion, and mutual assistance. In addition to the team clusters, centrally located facilities (including a large conference room, copy facility, mail room, and lunch room) are intended to enhance contact among all employees in the building.

The Entry Center will also encourage spontaneous encounters by providing spaces and features designed to enhance visual access and provide comfortable short term places for conversations, including elbow "perches" against which one can lean. An expanded field of view in these areas will also provide a way for staff to watch other people in the environment, thereby increasing opportunities to engage others in spontaneous meetings.

The Entry Center badging stations, to be used by staff when they are engaged in badging and training activities, are designed to increase productivity. Each badging station allows an employee to serve two customers simultaneously, offers photography and fingerprinting capability, and uses video computer terminals to provide orientation training. 


\section{PNL's ACL Mezzanine Offices}

One of the primary design goals for the central open office area in PNL's 325 Building mezzanine was team unity for the production, planning, and control (PP\&C) administrative clerks. Before the office renovation, the clerks were separated into two office spaces by the type of projects on which they worked. Facility programming interviews showed that the clerks had a strong preference for being together; indeed, they stated that they needed constant access to each other to perform their tasks well. The new design placed the clerks in a centrally located open office area. Individual work stations are separated by low panels over which the clerks can see and talk to each other. Tall panels separate the clerks from the view of employees using the copying equipment in the open area. After renovation, the PP\&C clerks report team cohesion and association: ". . it has made us a more productive team. It has given us an identity."

\subsection{Workforce Health}

Illness, including stress-related problems, results from improperly designed environments as well as from high work demands coupled with low control over job processes (Karasek and Theorell 1990). Strategies to improve health need to be directed at the environment and work characteristics as well as organizational norms that influence the perceived level of work demand (e.g., taking a break is not appropriate). Research suggests a wide array of approaches to health issues, from providing health facilities to creating positive feelings to reduce stress.

\subsubsection{Sick Building Syndrome}

Illness results in significant losses in productivity for American business. Although work environments in America are usually believed to be relatively comfortable and safe workplaces, buildingrelated health complaints have been reported with increasing frequency in several Western countries in recent years (Hedge et al. 1987). Usually the complaints are nonspecific and diverse, typically including aching joints, muscle pain, heartburn, chest tightness, sinus trouble, dry mucous membranes, noticeable odors or musty smells, dirty air, sneezing, congestion, sore throat, contact lens difficulties, watering eyes, humidity too high or too low, sleepiness, mental fatigue, dizziness, nausea, headaches, and cold/flu-like symptoms. These complaints are not any different from everyday health problems, but in the work environment they are increasingly associated with a particular building or work setting.

Buildings that have been associated with symptoms of ill-health have been described as "sick" buildings. In temporarily sick buildings, the onset of symptoms is acute, but the prevalence of symptoms declines over time, with most problems ceasing within one year of occupancy. In permanently sick buildings, symptoms persist over time; however, they commonly cannot be attributed to any specific air contaminant. Indeed, measurements of indoor air quality in permanently sick buildings typically have failed to find evidence of significant pollutants (Robertson et al. 1985; Hedge et al. 1986). 
Some factors that have been linked to sick building syndrome include 1) indoor climate, i.e., temperature, humidity, air-flow, noise, lighting, and office furniture ergonomics (Sterling et al. 1983;

Tavris et al. 1984; Skov and Valbjorn 1987); 2) office layout, i.e., number of workstations in a space, open-plan layouts, deep-plan layouts (Skov and Valbjorn 1987); and 3) social and psychological factors, i.e., occupational stress and personal control (Kemery et al. 1987; Motowidlo et al. 1986).

\subsubsection{Work Stress}

The physical work environment can play a role in reducing work stress, a growing issue for business. The National Council on Compensation Insurance (tracking activity in 32 states) contends that mental stress claims have increased fivefold in the past five years (Friedman 1991, p. 25). Offerman and Gowing (1990) note that more and more workers have begun to sue their companies for compensation for work-stress-related illnesses. Further, the American Medical Association estimated in 1988 that 80 percent of U.S. medical problems are stress-related (Freidman 1991).

While some stress is beneficial and stimulates activity and performance, increased stress in the workplace tends to accumulate over time, building from constancy and duration of strain rather than from the stress associated with major events (which is the measure corporations commonly use to assess stress) (Friedman 1991). When stress increases, it leads to poor job performance, absenteeism, employee dissatisfaction, high turnover, withdrawal, and a variety of health problems (Rossi and Lubbers 1989). These stress-related outcomes decrease organizational effectiveness and competitiveness. Stressed workers are also known to carry their negative moods and fatigue into home life (Frankenhauser 1982).

Although stress from other factors (e.g., financial pressures, family problems) is not directly related to the work environment, these difficulties, as well as the stress related directly to work, are likely to have an impact on an employee's performance at work. Thus, any environmental features that reduce work-caused stress may also ameliorate stresses caused by other factors.

\section{Relaxation Opportunities}

Frankenhauser (1982, p. 18) recommends that organizations provide opportunities for "slow unwinding" so that workers can overcome fatigue and other negative consequences of stressful work. The work environment can be designed to provide opportunities for slow unwinding. In a study for Steelcase, Inc., pollster Louis Harris (1988) found that many workers did not feel they had a place to relax during the day. The Chicago Police Department recently took the need for relaxation to heart. Their new Emergency Communications Center will contain a relaxation room which was specifically requested (and vociferously fought for in budget hearings) to help provide relief from a highly charged and frenetic work setting. ${ }^{(\mathbf{a})}$

(a) Heerwagen, J. Personal communication with C. Guerlack, Chicago Police Department, November 1990. 
Karasek and Theorell (1990) discuss the importance of "strain relievers" in work settings, which they describe as opportunities to engage in informal rituals that relieve tension. Without the periodic return to a rest state, people become less and less capable of taking on difficult tasks. Opportunities provided for relaxation and strain relief need the support of organizations also. If norms and values in an organization make it difficult for employees to take advantage of such opportunities, because they do not want to be seen as "loafing," then the benefits are not likely to be realized.

\section{Contact With Nature}

Another environmental feature found to be associated with psychological relaxation is contact with nature. Employees whose workstations have access to a window view of the outdoors are less stressed at work than those who have a window looking out upon a built scene only or who do not have a window. Ulrich (1984) studied matched groups of patients, one whose window view was a grove of trees and the other whose window view was another hospital wing. Patients with the tree view stayed in the hospital for a significantly shorter period of time, took fewer strong analgesics, and had a more positive post-surgery recovery (as noted in an archival search of nurses' records). Schielberg (1990), in a study of personalization of work stations, found that workers often put up nature posters which they found soothing to look at.

In many environments, opportunities for contact with nature are limited because of the number of interior offices located away from window walls. Furthermore, except for plants workers bring in, indoor plants are not widely used to compensate for lack of contact with nature. For instance, an evaluation of seven Pacific Northwest office buildings found that close to half of the occupants decorated their workspaces with plants and flowers (Heerwagen et al. 1991).

\subsubsection{Personal Control}

Perceived and actual control over the environment and social interaction are factors that affect job performance (especially in high-demand jobs) and well-being at work (Karasek and Theorell 1992; Sherrod 1974) and may be a determining factor in reported symptoms of poor health in the workplace (Hedge et al. 1989). Important environmental control components in the environment-behavior relationship include, among others, individual's control over other's access to them, ability to attain privacy when desired, freedom to move about, being able to control local ambient conditions (lighting, temperature, noise), and freedom to decide how to perform job tasks. Personal control operates as a mediating variable that contributes to an individual's cognitive evaluation of an environment (Schmidt and Keating 1979). Hence, although the work environment creates a basic condition, social and dispositional factors influence people's judgment of a situation. Stated another way, "the environment produces a negative affect when social or physical factors reduce the amount of perceived [and actual] freedom and control" (Schmidt and Keating 1979, p. 684).

The perception of lack of control is associated with a range of outcomes. In a seminal study, Glass and Singer (1972) found that perceived control significantly reduces adverse behavioral aftereffects of exposure to environmental stressors such as noise. More recently, research conducted by 
Frankenhauser and Johansson (1986) suggests that the inability to personally control work demands unfavorably affects hormonal stress reactions. Perceived control has been shown to mediate the negative effects of highly dense settings on complex cognitive tasks and problem-solving persistence. In Sherrod's study (1974), the freedom to choose to leave a densely occupied setting improved employee performance, even though individuals free to move chose not to leave. Research on the relationship between density, crowding, and perceived control conducted by Schmidt and Keating (1979) suggests that a dense environment is likely to be perceived as crowded when occupants perceive or experience a loss of control.

Perceived and actual control are also closely tied to privacy (i.e., the regulation of social interaction). For example, a study by McCarrey et al. (1974) found that people working in an open office felt they had little control over the environment and, thus, did not have auditory or visual privacy, nor were they able to have confidential communications. Control also means the ability to personalize one's own workspace (Sundstrom et al. 1986) and control the ambient conditions of the individual workspace. The perception of individual control affects even our sense of thermal comfort. When people believe they can control their environment or even broader aspects of a situation, they report being comfortable in cooler than normal temperatures.

\subsubsection{Ergonomics}

Investments in ergonomics programs provide another way of reducing costs associated with musculo-skeletal strain and other problems created by an inappropriate fit between employees and their immediate work environment. Costs have mounted dramatically over the past decade for claims associated with injuries attributed to the ergonomics of the work environment. Total costs for cumulative trauma disorders (such as carpal tunnel syndrome) vary markedly depending on when costs are tabulated in the development of the illness, from an average annual cost of $\$ 20$ billion to U.S. business (McCloud 1994) $)^{(\mathrm{a})}$ to $\$ 49$ billion annually (Alexander 1994). ${ }^{(b)}$ The average medical cost and lost wages for cumulative trauma disorders is estimated to be $\$ 29,000$ per person; costs to industry for lower back problems are estimated to be $\$ 1$ billion annually (Alexander 1994). ${ }^{\text {(b) }}$

A number of reputable companies have developed ergonomics programs either to reduce the number of workman's compensation claims and associated costs or because they felt it made their product more competitive or desirable to the consumer (McKeen and Miller 1993). The most common industries in the survey (more than 15 percent each) were 1) electronics manufacturers, 2) food processors/pharmacists, 3) heavy manufacturers, and 4) information services providers. These industries comprise many of the larger companies in the country and tend to be the leaders in many aspects, including safety. This leadership may also be based on maintaining eligibility for government contracts by demonstrating compliance with specific existing or anticipated regulations.

(a) McCloud, D. Personal communication, January 1994. Ergotec, Minneapolis, Minnesota.

(b) Alexander, D. Personal communication, January 1994. Auburn Engineering, Auburn, Alabama. 
Workplace design influences body postures during the job, e.g., performing an assembly or packing task, working at a computer workstation, or performing precise tasks in a laboratory fume hood. Visual tasks, including those associated with computer work, can also place additional stresses on the neck and shoulders if viewing angles exceed ergonomic design guidelines (ANSI 1988).

\subsubsection{Computers and Health}

Insurance company, medical, and national labor statistics all indicate that ergonomic analysis and redesign of the workplace to eliminate risks of repetitive trauma disorders would be an effective way to reduce health care costs. For example, U.S. Bureau of Labor Statistics figures show that 56 percent of workers compensation injury claims are now due to computer repetitive strain injury, especially carpel tunnel syndrome (CTS). CTS can be permanently disabling and very expensive; a single claim can cost from $\$ 5,000$ to $\$ 100,000$ (depending upon the need for surgery).

With work more centered around the computer terminal, a number of related health issues are receiving attention. Repetitive strain injury is one of the fastest growing occupational diseases of the 1990s. The primary cause commonly cited is mouse and keyboard use. A report by the National Academy of Sciences (1983) concludes that most visual problems associated with computer use are related to inappropriately designed environments and not to the computer per se.

People working with computers experience a range of symptoms related to computing; e.g., eye problems, back and neck pain, wrist and muscle strain. Up to 50 percent of employees working with computers report health difficulties (Wineman 1982). In addition to the physical difficulties, high computer use has been associated with depression, anxiety, and fatigue (Smith et al. 1981; Winemen 1982). Employee unions have responded to these effects by launching nationwide campaigns for state regulations on problem areas for clerical workers, including guidelines on visual safety, human-machine interface, break periods, and ambient conditions.

\subsubsection{Health and Wellness Facilities}

Investing in people and health-promoting facilities and programs can mean avoiding additional costs associated with health claims for injury or work stress. A recent review by Gebhardt and Crump (1990) found that almost a third of U.S. firms with 250 or more employees now use fitness and wellness programs as a way to reduce health care costs. Many of these programs and their facilities are located on or adjacent to company property and contain equipment, space, lockers, and food facilities (promoting nutritional values at the same time).

Specific corporate reports also support the benefits of health-promoting programs and facilities. For example, an Eastman Chemical plant which adopted a health promotion program found that baseline data for 1992 showed a savings of $\$ 700,000$ in medical costs (Ainsworth 1993, p. 22). Managers of one Dow Chemical plant became convinced of the economic worth of its fitness center after comparing the cost, $\$ 62,000$ annually (beyond a small employee use fee), and the equivalent cost of one major illness such as a heart attack (Ainsworth 1993). Improvements in the health and functioning of 
employees also result in reduced absenteeism and injury. For instance, Gebhardt and Crump (1990) cite several studies which found that absenteeism dropped from 20 to 55 percent for companies which created fitness and wellness programs.

\subsubsection{Hanford Site Applications}

In preceding applications sections, the material has been organized by facility. In this section, however, the material is organized by issue in order to link the application more clearly to the research.

\section{Sick Building Syndrome/Indoor Climate}

Staff located in the mezzanine of PNL's 325 Building were experiencing a number of the symptoms of a "sick" building. Employee symptoms could not be attributed to any new construction or remodeling. As in the case of other permanently sick buildings, the symptoms could not be attributed to any specific air contaminant and persisted over time. In fact, some staff members' health improved while away from work, but the conditions would return during the working week. While air quality measurements found no evidence that exceeded the American Society of Heating, Refrigerating, and Air Conditioning Engineers (ASHRAE) standards, employees reported a number of negative symptoms they experienced while at work. The survey indicated that 40 percent of the staff surveyed experienced headaches; 33 percent experienced congestion and sore throats; and 27 percent experienced sinus trouble, uncomfortable temperatures and drowsiness.

Because of the high levels of symptoms experienced by the staff, losses in staff time, and perceived performance loss, a major renovation was undertaken. Specific design activities occurred as a direct result of the survey. These activities included removing and replacing the ventilation system during remodeling (including replacing noise attenuation features in the offices) and selecting work stations in the open office area to match job task demands and worker needs. Since the remodeling, no complaints have been registered.

\section{Personal Control/Work Stress}

Entry Center. The program for the proposed Entry Center addresses environmental elements thought to ameliorate work stress, including high levels of control over the environment, contact with nature, relaxation opportunities, and privacy regulation. Employees will be able to open their windows to the exterior, control the temperature in their offices, and adjust the type and amount of illumination in their office. Private offices also provide employees with the ability to regulate visual and auditory privacy.

PNL's ACL Mezzanine Offices. Employees participating in planning the open office area of the 325 Building mezzanine specifically requested a design that would provide them the perception of control over their workspace. The PP\&C clerks wanted to control access to a large number of file cabinets to which other staff had previously had open access. They wanted the design of the workspace 
to communicate their control to others. As a result, the file storage areas were located at the rear of the office area in full view of the PP\&C clerks, a front "reception" style counter was located at the entrance to the open office, and a small round peninsula table was placed adjacent to the entry counter to signal the work area to be used by those needing assistance.

Health and Wellness Facilities. Newer buildings serving DOE contractors at Hanford include shower and locker rooms. These facilities support employee fitness activities.

HEHF and Contractor Industrial Hygiene. Through the Hanford Environmental Health Foundation (HEHF), the Hanford Site provides diagnosis and remediation services. In addition, each contractor employs industrial hygienists and laboratory safety specialists to provide a safe workplace. These services are focused on remediation and prevention. The contractors also support health programs such as the Sagebrush Games. The next logical step is to promote health through employer-provided fitness centers, work environment redesign, and participatory planning.

Contact with Nature. Like PNL's EESB and ISBs I and II, the Entry Center specifications maximize windowed offices by including interior courtyards as well as interior windows, thereby connecting employees to nature and sensory variability. The Entry Center will also include an attractive lunch room adjacent to an outdoor patio.

Relaxation. Areas in which people relax are harder to find. While most of the newer Hanford buildings include "interaction spaces," "breakrooms," and/or lunchrooms, these spaces are rarely used for relaxation except for lunchtime eating and card games. The interaction spaces frequently discourage use during the non-lunch hours through their location (across from managers' offices where staff would be seen "off task") and their design (e.g., minimal visual and acoustic privacy and, in the case of numerous lunchrooms, in their stark institutional interior design).

\subsection{Organizational Commitment}

Lack of employee loyalty to a company clearly affects the economic bottom line in employee turnover and absenteeism. Employee commitment to an organization may also affect appropriate use and maintenance of company resources and willingness to go above and beyond the call of duty; it undoubtedly affects individual and group effort in task completion and employee promotion of the organization. The quaiity of the work environment and the quality and presence of associated facilities such as day care and health care facilities are linked directly to employee turnover and staff recruitment.

\subsubsection{Recruitment and Retention}

The Vision 2000 study produced by the American Institute of Architects (AIA) cites the workplace as one of the areas which will see major transitions by the year 2000 (AIA 1988). As numbers of 
white collar workers increase up to an estimated 50 percent of all jobs in 2000 , the report suggests that the nature and design of the workplace will play an important role in employee loyalty and turnover

rates:

Lack of loyalty to individual companies will be further incentive for employers to provide an appealing and healthy environment. For instance, it is full of baby boomers who have been raised with more affluence and education than any preceding generation of workers. They were the first generation to have a "room of their own" (figuratively and literally), and to take for granted aesthetic surroundings, spaciousness, and a certain level of luxury and privacy. (p. 57)

A study by Becker and Lynn (1986) supports this statement. They found that subjects in a job application experiment were more likely to select jobs associated with high-quality workspaces than with ordinary ones, even though these participants claimed that their decisions were based solely on job content.

Seiler (1984) cited specific design decisions made by management to communicate an organization's concern for its employee's physical and psychological well-being: a gallery around the assembly area, warm artificial lighting, effective air conditioning and circulation, pleasant break and lunch areas, location in a beautiful and historic setting, and convenient parking. The desired results were achieved as a long waiting list of applicants was generated despite strong competition for employees from other companies.

Using the environment to attract and retain high-quality staff is exemplified in the approach of Sandoz International, an international pharmaceutical company. At one of the company's R\&D laboratories, company architects and laboratory management stated that one of their design objectives for a new laboratory was to attract international scientists to the North Carolina laboratory. Sandoz met their recruitment objective--the laboratory employs noted scientists from many different countries and most of the world's continents. The laboratory facility goes far beyond providing scientists with the latest technology. The designers quadrupled the industry standard for linear benchtop from 12 linear feet to 48 linear feet. The design also enhanced the laboratory appearance (colored fume hoods and piping, etc.) and included extensive window access to the outdoors, curved interior hallways with lowered lighting and coordinated artwork, ample individual scientist office area (150 square feet), and small interaction alcoves located off the main corridor. ${ }^{(a)}$

\subsubsection{Turnover}

The work environment even impacts costly employee turnover. Among the factors recently found to be linked with reduced turnover is the presence of on-site and near-site family care facilities. Childcare facilities return investment to the company through reduced turnover and improved recruitment (Freidman 1991). Furthermore, the benefits which accrue from child care and elder care centers are

(a) Heubach, J. Personal tour, September 1993. 
likely to increase in importance, given the shifting size and composition of the American work force reported in Work Force 2000 (Johnston and Packer 1987, cited in Freidman 1991).

The cost of replacing employees is high; thus, reducing turnover can mean a significant reduction in corporate expenses. For example, loss of exempt staff costs organizations about 1.5 times the individual's annual salary and loss of non-exempt staff costs organizations about 0.75 times the annual salary for a given position (Schlesinger and Heskett 1991; Phillips 1989, cited in Freidman 1991). Furthermore, some researchers believe that figures on organizational losses from employee turnover markedly underestimate the true loss by not accounting for hidden costs, e.g., inefficiency of the new employee, inefficiency of co-workers, and inefficiency from vacancy of position (Freidman 1991).

\subsubsection{Hanford Site Applications}

\section{Child Care Facility}

Child care facilities may be particularly useful in recruiting top-level professional women who have young children. The DOE-RL has built a near-site child care center, and PNL is planning a day care facility to serve staff needs.

\subsection{Organizational Values and the Physical Environment}

The design of a working environment communicates organizational values and norms by serving as a medium for the message. The message this design communicates can encourage organizational commitment and performance, advance recruitment, influence staff interrelationships, stimulate individual motivation; communicate corporate valuing of employees; and, ultimately, affect individual employee performance. The message is communicated regardless of management intent and may or may not be an accurate message (Seiler 1984).

There is growing recognition and understanding of the relationship between design and the perception of organizational and human values. Schein (1990) identified the physical environment as one of the three fundamental levels at which organizational culture manifests itself. Organizations committed to world class competitiveness can design and use their working environments to maximize organizational effectiveness through attention to features which communicate the goals and norms of the organization.

The perception of a place is communicated through layout, appearance, and the look and feel of open space. This perception is also communicated by how space is used and by whom, and how attributes such as size and location are allocated to workers. These aspects of the environment can have a considerable impact on people's feelings of esteem, belonging, motivation, and team cohesion, as well as the sense of pleasure employees experience from the environment at work (Steele 1982; Sundstrom et al. 1986; Stokols 1990; Wineman 1982). 
Despite the increased interest in these psychosocial and symbolic impacts of the environment, relatively little research exists in this area. Stokols (1990) decried the lack of incorporation of local values, symbols, and culture needs in design which he feels should provide

. . . a context in which fundamental human values can be cultivated and the human spirit can be enriched. Environmental settings are designed not only to facilitate the smooth performance of everyday activities but also to provide places to which people are drawn by virtue of their symbolic and affective qualities. (p. 642)

In a similar vein, Schuler (1980) proposed that organizations cannot mitigate growing problems associated with stress unless they understand people's needs and values and how these needs and values relate to organizational or environmental demands and constraints. He defines psychological needs as "a healthy consciousness, e.g., sensory stimulation, self-esteem, and self-actualization" (p. 190).

\subsubsection{Communicating Organizational Values and Norms}

\section{Power, Status, Equality and Organizational Norms}

Allocation of work environment resources clearly communicates an organization's values and valuing of its employees. Distribution of work environment resources signals employee collaboration or competition, openness, and democratic or authoritarian norms. Movements toward employee empowerment and team performance can be supported by the design and use of the physical work environment.

Organizations have long used the physical environment to display status and power using the differentiation of office size, quality of elements (furniture, artwork, etc.), and locational attributes, including access to windows and access to important people and resources (Sundstrom 1986). In a recent article on the physical settings of work, Carnevale (1992) expressed the following view:

At a time when organizations appear interested in mobilizing the support and commitment of workers, the question arises whether a status-driven approach to settings management reinforces class distinctions. It is the experience of many that feelings can run deep on these kinds of issues and that they can take on significance far out of proportion to their apparent importance. Modern organizations seek collaboration, openness, democratic norms, shared meaning, and trust. Inordinate use of the features of physical settings as status symbols belies these ideals. (p. 431)

Steele (1982) identifies a number of environmental "power elements," including territorial boundaries and markers, social control through visibility, lack of a place of one's own, the use of lighting to create mood and focus, the use of corporate pictures (especially pictures of founding members) to 
portray a sense of conservatism or stability, control over access to resources, differentiation versus the integration of organizational units, constraints on movement and access, furniture quality and arrangement, and aesthetic appearance.

Another element communicating power or equality is the manner in which privacy is regulated. Many people work in open offices or cubicles where they have little ability to control people's access to them and where they cannot hold private conversations or work without distractions (Sundstrom 1986; McCarrey et al. 1974; Spreckelmeyer 1993; Sundstrom et al. 1982; Block and Stokes 1989; Heerwagen et al. 1990; Brookes and Kaplan 1972; Marans and Sprecklemeyer 1982). A study of faculty offices in a community college found that faculty were less available in open plan settings and that students rated the quality of their feedback lower than for faculty in private offices (Becker et al. 1983).

The ability to achieve privacy when wanted may be a fundamental human need that is not being adequately dealt with in work settings. Privacy appears to be a universally sought state of being, although the management and functions of privacy vary widely (Altman 1974, 1975; Westin 1967). While people vary in their means of achieving privacy, cultures around the world seek and attain privacy. Even preschool children show their preference for privacy and have a refined understanding of the use of the physical environment to attain privacy (Wolfe 1978; Laufer et al. 1974; Curtis and Smith 1974).

\subsubsection{Participation}

Participating in the design of workspaces is also increasingly recognized as a powerful way of building employee involvement, morale, and productivity. Studies of design projects which have included high levels of participation generally find that employees are more satisfied with environments (Brill et al. 1984). Even moderate levels of employee participation can reap significant benefits, which affect a company's economic bottom line (Imada and Hubert 1993).

A recent study by Imada and Hubert (1993) supports these claims. They found that employee participation in resolving workplace problems reduced environmental complaints and reduced total medical claims by 86 percent over the previous year's claims. The positive impact of participation was ascribed to changes in employees' perceptions of safety. Another issue was the impact of participation on employees' sense that their company cared about them and their well-being. In the Imada and Hubert study, employees were involved in monitoring environmental conditions and helping to develop ways to resolve problems.

Despite the studies, building design decisions are generally made by a small group of people who frequently do not elicit the views of those who will work in the spaces they create. The BOSTI studies (Brill et al. 1984) found that more than 80 percent of the office workers studied said they were not allowed to participate in planning and designing their workspaces, and 75 percent said they were 
dissatisfied with this level of participation. Harris (1988) found that neither managers nor designers wanted office workers to participate in the design decisions; whereas, 91 percent of the office workers felt strongly that they should be able to participate in design decisions that affect them daily.

Carnevale (1992) urges that workers be involved in design "both at the point when they are created and afterward when adjustments are needed in their use. In other words, the challenge is to involve managers and workers in settings design" (p. 432). According to Steele (1973), participation in design decisions:

. . . a) makes people more aware of the settings around them; b) inspires them to ask themselves what they are trying to do there; c) stimulates them to assess the appropriateness of their settings for what they want to experience or accomplish; and d) leads them to make appropriate changes (in either the setting or their own location, or by leaving it for a better one) to provide a better fit between themselves and the setting. (p. 8)

\subsubsection{Social Relationships}

Many organizations depend on team effectiveness and collaboration. Companies are structuring work around projects, both in a project organization and as loosely coupled organic networks (Morgan 1993). To be fully successful, these work teams require strong positive social relationships and specific project or team-oriented work environments. Further, increasing attention is being focused on workers who analyze, create, decide, and act on information, often collaboratively. In addition, the importance of such workers to organizational competitiveness is increasingly recognized. Recently, these workers have been called "knowledge workers."

In addition, having warm and friendly social relations at work is one of the most important factors in people's overall response to their jobs and work life (Karasek and Theorell 1990; Crouch and Nimran 1987). Although the environment cannot make people like one another, specific design features can encourage or inhibit the development of social relations (Bechtel 1977). Of central importance is the capacity of the environment to support different kinds of social interactions and the ability of people to control the amount, type, and degree of contact they have with others (Becker 1985; Holahan 1976). Interactions among workers are key features in efforts to facilitate new team work processes, increase feelings of empowerment, and develop mutual support systems.

Because much of our daily discourse with others is brief and merely "touching base," environments should provide places where people can have a quick conversation without distracting others. In most cases, these conversations will be held while walking or standing in an open or public space such as corridors, doorways, mail rooms, and copy centers. At other times, people may want to talk for somewhat longer periods of time, but not formalize or extend conversations by sitting down. Desirable places would allow people to perch or rest for five or ten minutes away from others. Such places might include corners, nooks, counters, or walkways overlooking a courtyard, stairway, or atria. Since these brief encounters are often of a private nature (e.g., discussing what went on in a meeting), people do not want to be easily overheard by others. 
The environment should also provide places where extended conversations can occur in either totally private places (e.g., conference rooms, team meeting areas) or social places such as lounges, cafes, or lunchrooms. To encourage their use, these intentionally designed social places should be centrally located and visually attractive, but not overly designed. Overdesigning social places discourages spontaneity and the sense of discovering a private place.

While "interaction spaces" have become a common element of office design, the spaces are all too often ill-conceived and rarely used because they do not respect basic aspects of employee interaction and characteristics of the physical environment that contribute to or detract from interaction (e.g., the relationship between visual access/exposure, the desire for brief encounters, and the need for auditory privacy).

The role of the aesthetic features of the environment on social behavior is not as documented as the effect of specific kinds of spaces. Nonetheless, there is evidence that aesthetically pleasant environments influence social interactions in a positive way. For instance, work by Holahan (1976) in a hospital psychiatric unit revealed that aesthetic improvements (e.g., brighter colors, attractive furnishings) to the environment had positive social impacts; the amount of nonsocial passive activity by patients decreased significantly at the same time that positive interactions between nurses, visitors and patients increased significantly. Classroom settings have produced similar results (Sommer and Olsen 1980). In a room designed to be softer and more conducive to face-to-face interactions, Sommer and Olsen found increased discussion and more positive feelings about the class. This result was true in the original study and in a revisit to the "soft classroom" 12 years later (Wong et al. 1992). In another classroom study, the presence of posters, soft colors, and interesting artwork was associated with increased student involvement in class discussions and also with higher performance on tests (Wollin and Montagne 1981).

\subsubsection{Image and Attributions}

Organizations' recognition of the power of their facilities to portray the corporate image is reflected in their investing large sums of money to produce images consistent with their organizational philosophy and goals. Most of this effort is spent on building exteriors and immediate entry spaces, such as lobbies and atria. Much less attention has been given to the image projected by the spaces in which most work is conducted. Becker (1985), in an analysis of quality work environments, contends that image must deal with such questions as, "Is the office environment congruent with a worker's professional identity and expectations, does it support and enhance a worker's sense of dignity and the organization's standing with its staff, clients, community, and competitors?" (p. 52).

Research by Sanoff (1986) in work settings and Werner et al. (1989) in housing suggests that people viewing an environment attribute specific characteristics to those living and working in the space consistent with the image projected by the place. Cherulnik and Koening (1989) found that highquality work environments were associated with positive perceptions of the people working in them; whereas, those in lower quality spaces were rated less favorably on a number of qualities, such as neatness and self-reliance. In a study manipulating aesthetic features of a private faculty office, subjects 
rated the professor much more positively and said they would feel better seated in the room when it was neat and contained plants and wall posters than when it was messy and did not have the plants and posters (Campbell 1979).

In a manufacturing situation, Teradyne Connection Systems (TCS) management wanted its new facility to help communicate the high value placed on its assembly process. Consequently, the proposed designs all used the assembly area as the focal point of the building. In addition to central location, the assembly area was an attractive and highly visible place to work.

\subsubsection{Positive Work Affect and Environmental Pleasantness}

Numerous studies of work settings have found that ratings of environmental pleasantness are significantly related to positive feelings about work (Sundstrom et al. 1982; Turnipseed 1992). New studies are showing increasing evidence that, in addition to creating positive feelings about the environment and organization, aesthetically pleasant places have a number of other positive impacts. The perceived pleasantness of the environment is associated with increased social interactions (Sommer and Olsen 1980), "unfreezing" of behavior patterns (Holahan 1976), increased performance on some tasks (Wollin and Montagne 1981), more positive attitudes (Wollin and Montagne 1981), reduced depressed moods (Smith et al. 1987) and anxiety (Turnipseed 1992).

As noted previously, aesthetically pleasing design features include variation in sensory conditions (color, texture, light, tactile sensations), soft colors and rounded surfaces, access to nature (including plants, trees, daylight, sunlight), interesting focal points and places from which expansive views can be obtained, and culturally relevant symbols. While no consistent affects are found for the use of specific colors, building occupants prefer freshly painted work environments (Wise and Wise 1988). The expenditure of company resources for paint, together with the fresh, clean environment it creates, communicates care and respect for occupants.

An aesthetically pleasing environment need not be expensive. Organizations can use simple and inexpensive design elements to foster employees' perceptions that the organization cares about them. Fresh paint, posters, plants, cleanliness, paintings, wall murals, the use of soft colors and accent colors, variable textures and lighting, and interesting window views are all well within the design budgets of facilities departments and are basic components of good design.

Although it is certainly possible to spend extraordinary amounts of money on glittery atria, commissioned works of art, and expensive furnishings, post-occupancy evaluations or anecdotal accounts of people's response to buildings do not indicate that these costly features are any more successful in producing positive responses than simpler and less costly solutions. In fact, just the opposite may be true if the design is perceived as overly extravagant or too modern and cold-looking. 


\subsubsection{Hanford Site Applications}

Again, to link the application more clearly to the research, the following material is presented by issue rather than by facility.

\section{Democratization of the Workplace}

Entry Center. The specification for the Entry Center calls for democratization of workspace and elements. All employees will have private offices; managers' offices are only slightly larger in order to accommodate meetings around a table. However, the furnishings and other amenities, such as windows, will be made available equally to all employees.

\section{Participation}

The Entry Center. The Entry Center design project gathered information in meetings and interviews to solicit work flow direction, job task descriptions, work load estimates, and work redesign. This input was used in developing the behavior-based facility specification. In addition, the core team will participate in the design review process along with the developer, designers, project manager, and environmental psychologist.

Analytical Chemistry Upgrades Program Planning. The participatory design process used in the Analytical Chemistry Upgrades Program also solicited information in meetings, interviews, and laboratory tours to identify goals, problems, and needs. Project managers, exempt laboratory researchers, and technical laboratory staff reviewed the collected information, participated in design review meetings, and recommended design layouts and features. The participatory design process resulted in laboratories and office environments which meet the needs of the staff and engender a feeling of ownership and pride. The positive affect and perceived productivity outcome of the process are reflected in one occupant's statement: "The attitude has chianged from one of embarrassment and apology for the facility to one of pride in being part of a group responsible for accomplishing positive changes."

\section{Social Support}

Entry Center. The principles of social interaction are readily seen in the specification for the Entry Center. It calls for a range of social places and opportunities, including private offices, "conversation nooks, team work rooms, and a pleasant lunchroom adjacent to an cutdoor patio.

\section{A Sense of Caring}

PNL's ACL Mezzanine Offices and Laboratories. The renovated mezzanine in the 325 Building communicates organizational concern for employees through the aesthetic design features themselves 
(i.e., interior wall lighting, plants, floor materials [tile and carpet], breakroom decor, conference room facilities, etc.), the design of the workplace to fit functional operation and individual work station needs, and the comprehensive participatory planning process which involved mezzanine employees.

Innovative laboratory designs are stepping beyond the state-of-the-art technological approach in providing laboratory settings that are designed to stimulate positive affect. ${ }^{\text {(a) }}$ At Hanford, color is being introduced into the Westinghouse Hanford Company's $222 \mathrm{~S}$ laboratories. The view length at PNL's ACL renovated laboratories is purposely varied to increase perceived environmental complexity; interior windows and glass block walls are included to increase perceived spaciousness in windowless settings; surface texture is varied; and pattern is introduced to add visual interest, complexity, and aesthetic appeal.

Entry Center. Quality of work life is one of the primary goals of the DOE's proposed Entry Center. In addition to task-congruent work station design and effective and efficient work environment layout, the interior character of the building will engender positive affect in Entry Center staff and visitors. The following features have been specified to generate environmental pleasantness and the feeling that the DOE cares about its employees:

- The hallway illumination will be reduced to provide variety and calmness and to save energy.

- The soft colors and textures of the natural desert environment will be carried throughout the building.

- Framed posters and displays will add interest and visual appeal and provide clues for finding various locations within the building.

- Short curved or angled hallways will be used to create a feeling of group cohesiveness and community and reduce the institutional feeling created by long straight hallways.

\section{Image and Attributions}

PNL's Administration Building. Corporate recognition of the role of the physical environment in communicating a desired image can be seen in numerous buildings of the Hanford contractors. PNL's administration building is surrounded by carefully groomed green landscaping in the midst of the surrounding arid steppe, extensive ponds and fountains in the desert, and the public access auditorium located in the center of the ponds and fountains. All of these symbols communicate corporate success. Interestingly, at the workshop conducted as part of the Entry Center planning process, a number of participants said they wanted the Center grounds to have a "PNL look" with trees and grass.

(a) Heubach, J. Personai tour of Sandoz-Mallard Creek Research Center, Raleigh, North Carolina, September 1993. 
PNL's ACL Upgrades Renovations. Exceptionally well-designed interior spaces can also be used to communicate within branches of the same corporation and as a medium to communicate with current and potential external clients. Both the renovated laboratories and the mezzanine office areas in the Analytical Chemistry Laboratory's 325 Building are sites for frequent dignitary tours, including the Under Secretary of Energy, corporate CEOs, and potential major clients. 


\subsection{Summary}

The research summarized in this report shows that the design of the physical work environment and the processes used to arrive at design decisions affect an organization's performance and its employees' well-being. The research cited also shows that many important organizational goals and objectives normally attributed to organizational structure and policies (e.g., team effectiveness and task efficiency) can be significantly affected by work environment design and planning processes. Further, the research shows that investing in high-quality facilities which match people's needs and preferences can have considerable economic payoffs in terms of reduced turnover, reduced health care use, increased work performance, and enhanced job satisfaction. The designed environment can also engender a feeling of esteem and motivation that is associated with positive feelings about and commitment to the organization.

The main findings summarized below come from environment-behavior and organizational research in a number of areas and fields: work process layout, human factors/ergonomics, facilities planning, group and team structure, perception, environmental psychology, industrial/organizational psychology, architecture, business management, communication, anthropology, and engineering. The findings show that the environment plays an active and mediating role with other factors in individual and organizational performance, employee well-being, job satisfaction, cognitive functioning, team effectiveness, turnover, recruitment, and the image communicated within and outside the organization. While the research cited in this review used office environments primarily, the environment-behavior and design principles translate as well to many other types of work environments, e.g., factories, laboratories, and maintenance facilities.

\subsection{Performance}

The designed environment has both direct and indirect effects on individual work performance and organizational effectiveness/productivity. The environment acts in a direct way by creating conditions that make work easy or difficult. Work stations can create physical strain which results in lost efficiency and time, medical claims, and interrupted communication. Work stations that fit the job tasks like a glove can also be created. The physical layout of the work process for both manufacturing and office settings significantly impacts productivity. Productivity gains can occur by designing the work environment to support 1) frequency of use, 2) functional grouping, 3) sequence of use, 4) efficient traffic patterns, and 5) communication needs. Productivity gains can be massive, as seen in Chrysler Corporation's regaining the $\$ 1$ billion cost of its new R\&D facility in a 3-year period. However small, increases in efficiency gained through work environment design add significantly to the economic bottom line because of the tremendous cost of labor. Any improvement gives the corporation a significant return on investment.

A great deal of effort is currently being undertaken to understand how to design work environments that foster the creativity and higher cognitive functioning of "knowledge workers" (i.e., employees 
who analyze, create, synthesize, decide, and act on information). Researchers are investigating interaction patterns, idea generation, project completion, and the behavior styles of knowledge workers in a variety of team work spaces: small team rooms, team office co-location, and permanent team project display space.

\subsection{Well-Being}

The design of the environment also affects health and performance by affecting physiological health and psychological processes, including motivation, mental stimulation, and attention. Although a great deal of attention has been paid to the direct impacts of environments on health and performance, less is known about the relationship between the environment and the psychological processes that mediate performance and health outcomes.

\subsubsection{Personal Control}

Issues of control over the environment show up repeatedly in many studies. When people have high levels of control, they are less likely to experience negative attitudes and feelings (including stress); and they are more likely to be satisfied with their jobs, perform better at tasks, and experience greater satisfaction with their environments. Control issues include having a private office where the door can be closed, having multiple places to experience (including relaxation facilities or quiet rooms if one does not have a private office), being able to adjust conditions to meet personal preferences and task needs, and being able to personalize one's workspace.

Control is not solely a feature of the environment, however. It also depends very much on an organization's willingness to grant control to workers. If the organization expects employees to remain at their desks rather than take advantage of moving to new locations to work or rest, the design will not accomplish its goals.

\subsubsection{Participatory Design}

Participation in design decisions produces outcomes similar to control. Participation is highly valued by workers, but is seldom used by management and design teams, despite the positive effects it has on employee attitudes toward an organization and their satisfaction with the new environment. Participation is also likely to yield a better fit between the person and task, thereby improving work performance and productivity. Like control, participation is an organizational issue.

In developing participation policies, organizations should be aware that "mock" participation is readily perceived as an empty promise. Real participation means engaging in joint decision making and problem solving, not just in asking for opinions that are filed away and never used. An excellent example of the participatory process is provided in the Imada and Hubert study (1993), which involved employees in identifying and solving an environmental problem. After the participatory approach, health and injury complaints dropped to zero for the 8-month period after the intervention. 


\subsubsection{Job Satisfaction, Work Stress, Sensory Stimulation}

A number of design features have multiple positive outcomes, ranging from positive affective functioning to enhanced task performance. These features include a high degree of enclosure and privacy; aesthetically pleasant surroundings; sensory variability and stimulation; sufficient personal space, including storage and work surfaces; a range of spaces that allow for a variety of social interactions among workers; contact with nature; and visual access to the surrounding environment, without feeling simultaneously "on view."

At first glance, the benefits of these environmental features may seem to be intuitively obvious. Yet many work settings are designed as if aesthetics did not matter. Investment in aesthetics is viewed by far too many organizations as an expensive frill with little or no return on investment. The neglect of the psychological and aesthetic features of the environment may also be a function of perceiving people as adaptable; i.e., the idea that giving employees a desk, a bit of space, a roof over their head, and shelter from bad weather should lead to their being able to function effectively. We have shown in this paper that aesthetics and sensory features of the environment are not mere frills. They are an integral component of a healthy, productive work environment.

The aesthetic pleasantness of the environment, including one's own workspace as well as public and shared spaces (conference rooms, lunch rooms), is positively related to affective functioning, job satisfaction, stress reduction, and perhaps cognitive functioning and organizational commitment.

\subsection{Image of the Organization}

The image projected by the physical environment not only affects the people working in it, but also the visitors and others whose perceptions of workers are congruent with the visual quality of the environment. Positive attributions are assigned to people working in pleasant, attractive, neat places; negative attributes are assigned to people working in unpleasant, drab, and untidy environments. To some extent, this image may be why many organizations invest so much money and design effort in their public spaces. Clients and important visitors generally experience only these public areas and do not see the back room where most of the day-to-day work occurs. Thus, visitors are filled with the aura of success and power associated with beautiful lobbies and expensively furnished board rooms. In the meantime, the employees note the contrast between the lobby and their own drab workspaces.

\subsection{Turnover and Recruitment}

The loss and retraining of employees result in tremendous costs to an organization. In a number of studies, work environment facilities have been shown to be linked to reduced turnover and improved recruitment, particularly for high-quality professionals. Corporations are now going far beyond offering state-of-the-art equipment to recruit top scientists; they offer aesthetically appealing laboratories, 
quadrupled benchtop work surface, management-size private offices, and multiple small team meeting areas surrounded by beautiful pastoral landscapes. In addition, research has shown that office appearance influences people's evaluations of the appeal of potential jobs. 


\subsection{Recommendation: A Call for Integration}

To derive the maximum benefit to the corporation, both managers and designers must integrate the organization and work environment into their planning. For too long, managers have ignored the impact buildings and their design have on long-term corporate success, and designers and facilities planners have ignored key organizational objectives and culture in designing work environments.

The process should be a truly interdisciplinary undertaking with an ecological orientation. An ecological approach looks at interconnections between events, procedures, people, and disciplines. A building is, after all, a habitat for people; and, like other natural habitats, is a complex system of multiple layers and levels of interactions.

\subsection{Corporate Strategy}

Corporations often limit the consideration of facilities to questions of the amount of available space in number of offices, the factory floor square footage, or the policy for assigning prime offices and office furniture by rank. By considering only a narrow range of the elements of any work environment, managers severely limit the potential benefit which can gained by integrating the environment into corporate planning. As stated by Seiler (1984), a Harvard professor who has taught in both the Graduate School of Design and the Harvard Business School:

Influencing behavior is almost all of what management is about, and buildings influence behavior. Failure to wring every benefit out of the most expensive capital asset most companies ever have would not be countenanced in any other aspect of corporate life. (p. 120)

Managers must begin asking, for any program or strategy, what environmental designs would support the change and the short- and long-term objectives. Managers must also be careful to avoid common practices which diminish the likelihood of a strong link between organization and environment. Seiler identifies common missteps:

- Commissioning a monument to the architect. It may not be sufficiently focused on work flow process or team effectiveness.

- Catering to the whims of top management. Building an adobe-type hacienda attached to the new building may be useless if the manager retires to the Southwest within a year.

- Trying to control costs by finding a turnkey agent to provide plans for a building of a prescribed capacity. Getting a building which fits neither the work process or organizational culture is ineffective. 
- Assigning a company executive to find the required space with minimum disruption, delay, and expense.

Another common practice which undermines the effectiveness of the organization-environment interdependence is designing based on the way the company conducted business in the past. For example, new organizational structures (project organization or the loosely coupled organic network) and the new era of espoused regard for employee empowerment call for different workplace designs such as numerous small project team meeting rooms.

Organizations can be proactive in integrating their organizational strategy and their work environment by requiring an assessment of the environmental linkages for each project whether it be short or long term. This effort may require the business to hire and/or train staff to work together with facilities planners and management as part of the corporate planning activities. In addition, managers need to support facilities planners and designers need to understand the company's values, traditions, caveats, cultural norms, goals, and procedures (Seiler 1984).

\subsection{Work Environment Planning}

All too often facilities planners use an architectural approach in which buildings are treated as technical problems or opportunities for artistic expression, not as strategic resources. In addition, work environments are not being designed and used effectively to enhance the productive capacity of an organization and the well-being of its employees. To obtain maximum benefit, facilities planners and designers must include corporate culture, corporate strategy, work process, and individual well-being into the planning and design process.

Facilities master planning is critical to the future productivity of a work environment and the quality of worklife for the occupants. However, organizational variables such as capacity variability, new work team structure, organizational culture, and work process simplification can exceed the expertise of traditional planning and design teams. Expanding the diversity of the planning and design team increases the likelihood of a good match between the work environment and the organization's goals and operation.

Traditionally, facilities planning teams include a facility programmer, project manager, architect/engineer, code consultant, financial consultant/cost analyst, equipment consultant, and site consultant. Recent recommendations from facilities planners suggest drawing from diverse fields in building multi-disciplinary teams: architecture, engineering, natural science, social psychology, environmental psychology, and strategic planning (Gibson 1993). Planning teams frequently omit technical staff, support staff, and line workers. Numerous studies of the benefits of employee participation in planning and design suggest including the people who will work in the building. Carnevale (1992) strongly advocates employee involvement: 
The design of work environments is not just a technical problem to be solved by distant experts who will never toil within the environmental milieu they create for others. To combat this problem, modern work teams must insist on having a meaningful say in the planning and design of work spaces before these spaces are occupied. (p. 432)

A recent planning and design project illustrates the use of a multi-disciplinary team engaged in an integrated planning effort to renovate a laboratory for a research organization undergoing programmatic change. When the Pacific Northwest Laboratory's Analytical Chemistry Upgrades Program planning team turned its attention to planning and designing the centralized Sample Receiving, Preparation, and Storage (SRPS) Laboratory, the design and research process problems exceeded the design solutions used in the previous state-of-the-art laboratory renovations. At this point, the program manager enrolled a human factors/environmental psychologist to help analyze work flow and complete a functional design program. The SRPS planning team adopted a linear programming process modeled after the Problem Seeking model of CRSS Architects, Inc. (Pena et al. 1987); i.e., they defined goals, facts, concepts, and needs and developed problem statements. Throughout the process, the ACL Upgrades Program Manager expanded the team beyond a traditional planning team to obtain needed expertise. The team included the project manager, the line manager, the architect, and the human factors/environmental psychologist, with a second ring of members including engineers, scientists and laboratory technicians, an industrial engineer, and an industrial/organizational psychologist.

The planning team examined organizational goals, process workflow, customer satisfaction, data management improvement projects, and laboratory performance measures. They also interviewed laboratory scientists and technicians and collaborated with line managers. In an iterative design review process, the planning team worked with the staff to review sketches and compare the sketches to workflow and design goals. The review also assessed the sketches for congruence with organizational objectives.

At each step of the design definition, the tearn met with staff to review and revise plans. The result is a laboratory that matches and streamlines laboratory workflow, provides a safe and unique sample storage system, provides a spacious workplace with interior windows which create openness in a setting with no exterior windows, minimizes the time lost and expense incurred from personal radiation monitoring, streamlines the delivery of samples to the laboratory, and creates an aesthetically pleasing and ergonomically appropriate setting for employees. The laboratory was completed at the beginning of 1994 and is awaiting its first sample. After an initial occupancy period, the laboratory will be evaluated to assess the degree of success in meeting the design goals, its service to customers, and the satisfaction of occupants. The laboratory provides a significant departure from even the standard state-of-the-art laboratory modules advocated by the country's best known laboratory designers. It is a custom-designed laboratory designed to meet the unique needs of the Analytical Chemistry Laboratory in a 40-year-old building. The comprehensive planning effort and iterative design review process were both engaged to provide the best possible work environment that will continue to influence positive behavior over its lifetime. 
Designers and facilities and operations staff can be proactive in integrating work environment research and design principles with the organization's strategic plan and improvement programs by requiring an assessment of the organizational linkages for each short- and long-term project. In integrated planning, designers and facilities planners would ascertain management's goals pertaining to the range of factors that the work environment affects and solicit input from employees related to the same range of factors. To be successful, managers need to support facilities planners and designers in understanding the company's values, traditions, caveats, cultural norms, goals, and procedures (Seiler 1984).

There is much remaining to be learned about developing effective work environments that are congruent with organizational goals, values, structures, and employee well-being. The research presented in this report lays a foundation for future work teams to collaboratively develop, design, and evaluate work environments. As stated by Edward T. Hall (cited in Carnevale 1992) almost thirty years ago:

What is needed, in the name of productivity (and employee well being) is rekindled interest in this overlooked topic and the granting of greater control to line managers and work teams over physical factors so that they cease to be the "hidden dimension" in organizational life. (p. 434) 


\subsection{References}

Ainsworth, S. J. June 7, 1993. "Chemical producers find employees' good health is good for business." Chemical and Engineering News, pp. 21-23.

Allen, T. J. 1970. "Communication Networks in R\&D Laboratories." R\&D Management 1:14-21.

Allen, T. J., and A. R. Fustfeld. 1975. "Research laboratory architecture and the structuring of communications." R\&D Management 5(2):153-163.

Allen, T. J., and P. G. Gersthberger. 1973. "A field experiment to improve communications in a product engineering department: The non-territorial office." Human Factors 15(5):487-498.

Altman, I. 1974. "Privacy: A conceptual analysis." In Man-Environment Interactions: Evaluations and Applications, ed. D. H. Carson. Proceedings of the Environmental Design Research Association (EDRA) Conference, EDRA 5. Environmental Design Research Association, Atlanta, Georgia.

Altman, I. 1975. Environment and Social Behavior: Privacy, Territoriality, Personal Space, and Crowding. Brooks/Cole, Monterey, California.

American Institute of Architects. 1988. Vision 2000: Trends Shaping Architecture's Future. AIA Press, Washington, D.C.

American National Standards Institute (ANSI). 1988. American National Standard for Human Factors Engineering of Visual Display Terminal Workstation. Human Factors Society, Inc., Santa Monica, California.

Archea, J. 1974. "Identifying direct links between behavior and its environment: Toward a predictive model." In Environmental Research and Aging, ed. T. O. Byerts. Gerontological Society, Washington, D.C.

Archea, J. 1977. "The place of architectural factors in behavioral theories of privacy." Journal of Social Issues 33:116-137.

Archea, J. 1984. Visual access and exposure: An architecturally mediated basis for interpersonal behavior. Unpublished doctoral dissertation. Pennsylvania State University, Philadelphia, Pennsylvania.

Bechtel, R. 1977. Enclosing Behavior. Dowden, Hutchison \& Ross, Stroudsburg, Pennsylvania.

Becker, F. D. 1990. The Total Workplace: Facilities Management and the Elastic Organization. Van Nostrand, New York. 
Becker, F. D., and M. L. Lynn. 1986. "The importance of office closure versus quality in job selection." In Proceedings of the Environmental Design Research Association, The Costs of Not Knowing, eds. J. Wineman, R. Barnes, and C. Zimring. Environmental Design Research Association, Atlanta, Georgia.

Becker, F. D. 1985. "Quality of Work Environment: Effects on Office Workers." In special issue, "Beyond the individual: Environmental approaches and preventions." Prevention in Human Services 4(1-2):35-37.

Becker, F. D., B. Gield, K. Gaylin, and S. Sayer. 1983. "Office design in a community college: Effect on work and communication patterns." Environment and Behavior 15(6):699-726.

Beer, C. T., and G. G. Darkenwald. 1989. "Gender differences in adult student perceptions of college classroom social environments." Adult Education Quarterly 40(1):33-42.

Bell, P. A., J. D. Fisher, and R. J. Loomis. 1978. Environmental Psychology. W. B. Saunders Co., Philadelphia.

Benedikt, M. L. 1979. "To take hold of space." Environment and Planning B 6:47-83.

Black, J. T. 1991. The Design of the Factory with a Future. McGraw-Hill, New York.

Block, L. K., and G. S. Stokes. 1989. "Performance and satisfaction in private versus non-private work settings." Environment and Behavior 21(3):277-297.

Boubekri, M., R. B. Hulliv, and L. L. Boyer. 1991. "Impact of window size and sunlight penetration on office workers' mood and satisfaction." Environment and Behavior 23(4):474-493.

Brill, M., S. Margulis, E. Konar, and BOSTI. 1984. Using Office Design to Increase Productivity. Vol. 1. Workplace Design and Productivity, Inc., Buffalo, New York.

Brill, M., S. Margulis, E. Konar, and BOSTI. 1985. Using Office Design to Increase Productivity. Vol. 2. Workplace Design and Productivity, Inc., Buffalo, New York.

Brookes, M. J., and A. Kaplan. 1972. "The office environment: Space planning and affective behavior." Human Factors 14(5):373-391.

Campbell, D. E. 1979. "Interior office design and visitor resfonse." Journal of Applied Psychology 64(6):648-653.

Canter, D., and C. Kenny. 1975. "The spatial environment." In Environmental Interaction: Psychological Approaches to our Physical Surroundings, eds. D. Canter and P. Stringer. Surrey University Press, London. 
Carnevale, D. G. 1992. "Physical settings of work: A theory of the effects of environmental form." Public Productivity and Management Review 25(4):423-436.

Champy, J., and M. Hammer. 1993. Reengineering the Corporation. HarperCollins, New York.

Cherulnik, P. D., and R. L. Koenig. 1989. "Perceptions of the workplace and perceptions of the worker: A potentially practical example of the influence of environmental setting on personal identity." In Changing Paradigms. EDRA 20, eds. G. Hardie, R. Moore, and H. Sanoff. North Carolina State University, Raleigh, North Carolina.

Cooper, R. 1968. "The psychology of boredom." Science Journal 4(2):38-42.

Crouch, A., and U. Nimran. 1989. "Perceived facilitators and inhibitors of work performance in an office environment." Environment and Behavior 21(2):206-226.

Curtis, E. F., and J. P. Smith. 1974. "Children in space." School Review 82:649-657.

Davenport, T. H. 1993. Process Innovation. Harvard Business School Press, Boston.

de Bono, E. 1970. Lateral Thinking: Creativity Step by Step. Harper \& Row, New York.

Feather, J. J., and K. F. Cross. 1988. "Workflow analysis, just-in-time techniques simplify administrative process in paperwork operation." Industrial Engineering 20(1):32-40.

Festinger, L., S. Schacter, and K. Black. 1950. Social pressures in informal groups. Harper \& Row, New York.

Fowler, R. L., W. E. Williams, M. G. Fowler, and D. D. Young. 1968. An investigation of the relationship between operator performance and operator panel layout for continuous tasks. Tech. Report. 68-170. U.S. Air Force AMRL (AD-692 126).

Frankenhauser, M. 1982. "Psychoneuroendocrine approaches to the study of stressful personenvironment transactions." In Selye's Guide to Stress Research, ed. H. Selye. Van Nostrand, New York.

Frankenhauser, M., and G. Johansson. 1986. "Stress at work: Psychobiological and Psychosocial Aspects." International Review of Applied Psychology 35:287-299.

Freidman, D. E. 1991. Linking Work-Family Issues to the Bottom Line. The Conference Board, Inc., New York.

GAO. See U.S. General Accounting Office. 
Gebhardt, D. L., and C. E. Crump. 1990. "Employee fitness and wellness programs in the workplace." American Psychologist 45(2):262-272.

Gibson, W. D. 1993. "Labs: A science in themselves." Today's Chemistry at Work 2(3):21-25.

Glass, D. C., and J. E. Singer. 1972. Urban stress: Experiments on Noise and Social Stressors. Academic Press, New York.

Goodrich, R. 1982. "Seven office evaluations." Environment and Behavior 14(3):353-378.

Gorman, J. 1992. "Finding the right fit." Interiors 15(4):52-55.

Gullahorn, J. T. 1952. "Distance and friendship as factors in the gross interaction matrix." Sociometry 15:123-134.

Hall, E. T. 1966. The Hidden Dimension. Doubleday, New York.

Harris, L. 1988. The Office Environment Index: Detailed Findings. Steelcase Inc., Grand Rapids, Michigan.

Hayes, R. H., S. C. Wheelwright, and K. B. Clark. 1988. Dynamic Manufacturing. Free Press, New York.

Hedge, A., E. M. Sterling, and T. D. Sterling. 1986. "Evaluating office environments: The case for macroergonomic systems approach." In Human Factors in Organizational Design and Management. Vol. 2, pp. 419-424, eds. O. Brown, Jr., and H. W. Hendrick. Elsevier, New York.

Hedge, A., S. Wilson, P. S. Burge, and J. Harris-Bass. 1989. "Work-related illness in office workers: A proposed model of the sick building syndrome." Environmental International 15:143-158.

Heerwagen, J., R. L ،amond, and J. Loveland. 1991. Energy Edge Post Occupancy Evaluation Project. Final Report. U.S. Department of Energy \#DE-AC06-86RLL11659 and Bonneville Power Administration \#DE-B179-90-BP04252. Bonneville Power Administration, Portland, Oregon.

Heerwagen, J., and G. Orians. 1984. "Adaptations to windowlessness: The use of decor in windowed and windowless offices." Environment and Behavior 18(5):623-637.

Heerwagen, J. 1990. "Light hunger, room brightness, and affective functioning." Environment and Behavior 22(5):608-635.

Herzberg, F., B. Mausner, and B. Snyderman. 1959. The Motivation to Work. Wiley, New York. 
Heubach, J. 1984. The effects of school setting visual space attributes, and behavior on eighth-grade students' evaluations of the appropriateness of privacy-related school situations. Unpublished doctoral dissertation. University of Washington, Seattle, Washington.

Holahan, C. J. 1976. "Environmental change in a psychiatric setting." Human Relations 29(2):155-166.

Imada, A. S., and R. J. Hubert. 1993. "Physical and psychological factors of safety: A macroergonomic case study." In Proceedings of the Human Factors and Ergonomics Society, Human Factors Ergonomics Society, Seattle, Washington.

Isen, A., M.M.S. Johnson, E. Mertz, and G. F. Robinson. 1985. "The influence of positive affect on the unusualness of word associations." Journal of Personality and Social Psychology 48(6):1413-1426.

Isen, A., K. A. Daubman, and G. P. Nowicki. 1987. "Positive affect facilitates creative problemsolving." Journal of Personality and Social Psychology 52(6):1122-1131.

James, L. A., and L. R. James. 1989. "Integrating work environment perceptions: Explorations into the measurement of meaning." Journal of Applied Psychology 74(5):739-751.

Karasek, R., and T. Theorell. 1990. Healthy Work. Basic Books, New York.

Katcher, A., E. Friedman, A. Beck, and J. Lynch. 1983. "Looking, talking, and blood pressure: The physiological consequences of interactions with the living environment." In New Perspectives on Our Lives with Companion Animals, eds. A. Katcher and A. Becker. University of Pennsylvania Press, Philadelphia, Pennsylvania.

Keep, P., J. James, and M. Inman. 1980. "Windows in the intensive care unit." Anaesthesia $35: 257-262$.

Kemery, E. R., K. W. Mossholder, and A. G. Bedeian. "Role stress, physical symptomatology, and turnover intentions: A casual analysis of three alternative specifications." Journal of Occupational Behavior 8(11):11-23.

Klitzman, S., and J. M. Stellman. 1989. "The impact of the physical environment on the psychological well-being of office workers." Social Science and Medicine 29(6):733-742.

Laufer, R. S., H. M. Proshansky, and M. Wolfe. 1976. "Some analytic dimensions of privacy." In Environmental Psychology: People and Their Physical Settings, 2nd ed., eds H. M. Proshansky, W. Ittleson, and L. G. Rivlin. Holt, Rinehart, and Winston, New York. 
Levinson, H. 1988. "You won't recognize me: Predictions about change in top-management characteristics." Academy of Management Executives 2:119-125.

Marans, R., and K. P. Spreckelmeyer. 1982. "Evaluating open and conventional office design." Environment and Behavior 14(3):333-351.

McCarrey, M. W., L. Peterson, S. Edwards, and P. von Kulmiz. 1974. "Landscape office attitudes: Reflections of perceived degree of control over transactions with the environment." Journal of Applied Psychology 59(3):401-403.

McKeen, R. G., and D. P. Miller. 1993. Benchmarking Corporate Ergonomics Programs for Sandia National Laboratories. Report \#SAND92-2667, Sandia National Laboratories, Albuquerque, New Mexico.

Moleski, W. H., and J. T. Lang. 1982. "Organizational needs and human values in office planning." Environment and Behavior 14(3):319-332.

Morgan, G. 1993. Imagination: The art of creative management. Sage Publications, Newbury Park, California.

Motowidlo, W. J., J. S. Packard, and M. R. Manning. 1986. "Occupational stresses: Its causes and consequences for job performance." Journal of Applied Psychology 71:618-629.

National Academy of Sciences. 1983. Video Displays, Work and Vision. National Academy Press, Washington, D.C.

O'Mara, M. 1989. "The physical setting as a scarce resource in organizations." Proceedings of the Environmental Design Research Association, EDRA 20, pp. 313-331. Environmental Design Research Association, Atlanta, Georgia.

Offerman, L. R., and M. K. Gowing. 1990. "Organizations of the future: Changes and challenges." American Psychologist 45(2):95-108.

Pena, W., S. Parshall, and K. Kelly. 1987. Problem Seeking: An Architectural Programming Primer. AlA Press, Washington, D.C.

Platt, J. R. 1961. "Beauty: Pattern and Change." In The Function of Varied Experience, eds. S. A. Maddi and S. R. Fiske. Dorsey Press, Homewood, Illinois.

Roberts, M., and G. T. Harris. 1989. "Wellness at work." Psychology Today 23(5):54-56. 
Robertson, A. S., P. S. Burge, A. Hedge, J. Sims, F. S. Gill, M. Finnegan, C.A.C. Picering, and G. Dalton. 1985. "Comparison of health problems related to work and environmental measurement in two office buildings with different ventilation systems." British Medical Journal 291:373-376.

Rossi, A. M., and C. A. Lubbers. 1989. "Stressed at Work." Aaohn Journal 37(7):258-264.

Russel, J. A., and A. Mehrabian. 1978. "Approach-avoidance and affiliation as functions of the emotion eliciting quality of an environment." Environment and Behavior 10(3):355-387.

Ruys, T. 1970. Windowless offices. Unpublished master's thesis. University of Washington, Department of Architecture, Seattle, Washington.

Sanoff, H. 1986. "The open office revisited." Proceedings of the Environmental Design Research Association, EDRA 17. Environmental Design Research Association, Atlanta, Georgia.

Schiller, G., E. Arens, F. Bauman, C. Benton, M. Fountain, T. Doherty, and K. Craik. 1988. "A field study of thermal environments and comfort in office buildings: Final report." ASHRAE 462-RP. University of California, Center for Environmental Design Research, Berkeley, California.

Scheiberg, S. 1990. "Emotions on display: The personal decoration of space." American Behavioral Scientist 33(3):330-338.

Schein, E. 1990. "Organizational culture." American Psychologist 45(2):109-119.

Schlesinger, L. A., and J. L. Heskett. 1991. "The service-driven service company." Harvard Business Review 65(5):71-81.

Schmidt, D. E., and J. P. Keating. 1979. "Human crowding and personal control: An integration of the research." Psychological Bulletin 86(4):680-700.

Schonberger, R. J. 1982. Japanese Manufacturing Techniques. Free Press, New York.

Schooler, C. 1984. "Psychological effects of complex environments during the life span: A review and theory." Intelligence 8:259-281.

Schuler, R. S. 1980. "Definition and conceptualization of stress in organizations." Organizational Behavior and Human Performance 25:184-215.

Seiler, J. A. 1984. "Architecture at work." Harvard Business Review 62(2):111-120.

Sherrod, D. R. 1974. "Crowding, perceived control, and behavioral after effects." Journal of Applied Social Psychology 4:171-186. 
Skov, P., and O. Valbjorn 1987. "The sick building syndrome in the office environment: The Danish town hall study." Environment International 13:339-349.

Smith, M. J., A. Happ, C. Stammerjohn, and B. Coker. 1981. An investigation of complaints and job stress in video display operators. Institute for Occupational Safety and Health, Cincinnati, Ohio.

Smith, S. E., R. O. Phil, S. N. Young, and F. R. Ervin. 1987. "A test of possible cognitive and environmental influences on the mood lowering effect of tryptophan depletion in normal males." Psychopharmacology 91:451-457.

Sommer, R., and H. Olsen. 1980. "The soft classroom." Environment and Behavior 12(1):3-16.

Speckelmeyer, K. F. 1993. "Office relocation and environmental change: A case study." Environment and Behavior 25(2):181-204.

Steele, F. 1986. "The dynamics of power and influence in workplace design and management." In Behavior Issues in Office Design, ed. J. Wineman. Van Nostrand, New York.

Steele, F. I. 1973. Physical Settings and Organization Development. Addison-Wesley, Reading, Massachusetts.

Sterling, E. M., and T. D. Sterling. 1983. "The impact of different ventilation levels and fluorescent lighting types on building illness: An experimental study." Canadian Journal of Public Health 74:385-392.

Stokols, D. 1990. "Instrumental and spiritual views of people-environment relations." American Psychologist 45(5):641-646.

Stokols, D. 1992. "Establishing and maintaining healthy environments." American Psychologist 47(1):6-22.

Stone, P. J., and R. Luchetti. 1985. "Your office is where you are." Harvard Business Review 63(2):102-117.

Sundstrom, E., J. P. Town, D. W. Brown, A. Forman, and C. McGee. 1982. "Physical enclosure, type of job, and privacy in the office." Environment and Behavior 14(6):543-559.

Sundstrom, E., R. K. Herbert, and D. W. Brown. 1986. "Privacy and communication in an openplan office." Environment and Behavior 14(3):379-392.

Sundstrom, E., K. P. DeMeuse, and D. Futrell. 1990. "Work teams: applications and effectiveness." American Psychologist 45(2):120-133. 
Tavris, D. R., L. Field, and D. L. Brumback. 1984. "Outbreak of illness due to volatized asphalt coming from a malfunctioning fluorescent lighting fixture." American Journal of Public Health 74:614-615.

Toffler, A. 1981. The Third Wave. Blanton, New York.

Tong, D., and P. Ellis. 1986. "Activity analysis: A case study of a new trend in office planning." In Proceedings of the Environmental Design Research Association. April 9-13. The Costs of Not Knowing. Environmental Design Research Association, Atlanta, Georgia.

Turnipseed, D. 1992. "Anxiety and perceptions of the work environment." Journal of Social Behavior and Personality 7(3):375-394.

Ulrich, R. S. 1984. "View from the window can influence recovery from surgery." Science 224:420-421.

Ulrich, R. S., R. F. Simons, B. D. Losito, E. Fiorito, M. A. Miles, and M. Zelson. 1991. "Stress recovery during exposure to natural and urban environments." Journal of Environmental Psychology 11:201-230.

Ulrich, R. S. 1993. "Biophilia, biophibia, and natural landscapes." In The Biophilia Hypothesis, eds. S. R. Kellert and E. O. Wilson. Island Press, Shearwater Books, Washington, D.C.

U.S. General Accounting Office (GAO), Federal Research. 1993. Aging Federal Laboratories Need Repairs and Upgrades. Document \#B-254151. Major contributors J. Wells, R.E. Allen, Jr., R. Cheston, and J. Johnson. Washington, D.C.

Werner, C. M., S. Peterson-Lewis, and B. B. Brown. 1989. "Inferences about home owners' sociability: Impact of Christmas decorations and other cues." Journal of Environmental Psychology 9:279-296.

Westin, A. F. 1967. Privacy and Freedom. Atheneum, New York.

Wineman, J. 1982. "Office design and evaluation: An overview." Environment and Behavior 14(3):271-298.

Winer, J. May/June, 1989. "Restoring calm to office space chaos." Management World, pp. 20-23.

Wise, J. A., and B. K. Wise. 1988. The Human Factors of Color in Environmental Design: A Critical Review. NASA Grant No. NCC 2-404, National Space and Aeronautics, Ames Laboratory, Moffett Field, California. 
Wolfe, M. 1978. "Childhood and privacy." In Children and Environment, eds. 1. I. Altman and J. F. Wohlwill. Plenum Press, New York.

Wollin, D. D., and M. Montagne. 1981. "College classroom environment: Effects of sterility versus amiability on student and teacher performance." Environment and Behavior 13(6):707-716.

Wong, C. Y., R. Sommer, and E. R. Cook. 1992. "The soft classroom 17 years later." Environmental Psychology 12:334-343.

Woodruff, D., and K. Lowry Miller. May 3, 1993. "Chrysler's Neon: Is this the small car Detroit couldn't build?" Business Week, pp. 116-126.

Young, R. H., and G. L. Berry. 1979. "The impact of the environment on the productivity attitudes of intellectually challenged office workers." Human Factors 21(4):399-407. 


\section{Distribution}

No. of

Copies

\section{OFFSITE}

12 Office of Scientific and Technical Information

\section{ONSITE}

Richland Operations Office

D. D. Green

Battelle Seattle Research Center

10 J. J. Heerwagen

Hanford Environmental Health Foundation

J. C. Conrad

ICF Kaiser Hanford Company

S. C. Calhoun

Westinghouse Hanford Company

S. M. Joyce
No. of

Copies

78 Pacific Northwest Laboratory

W. B. Brace

V. W. Briggs

W. W. Brown (5)

T. D. Chikala

K. M. DeMonia

K. J. Gaither

J. G. Heubach (15)

J. S. Hirsch

A. G. King

J. M. Latkovich

J. W. Leeper

J. C. Montgomery (5)

P. E. Moore

M. E. Olson

L. R. Pond

R. E. Rhoads

J. M. Rogers

J. A. Sanchez (5)

J. K. Simpson

J. W. Wald

W. C. Weimer (25)

M. A. Williams

Publishing Coordination

Technical Report Files (5)

Distr.1 

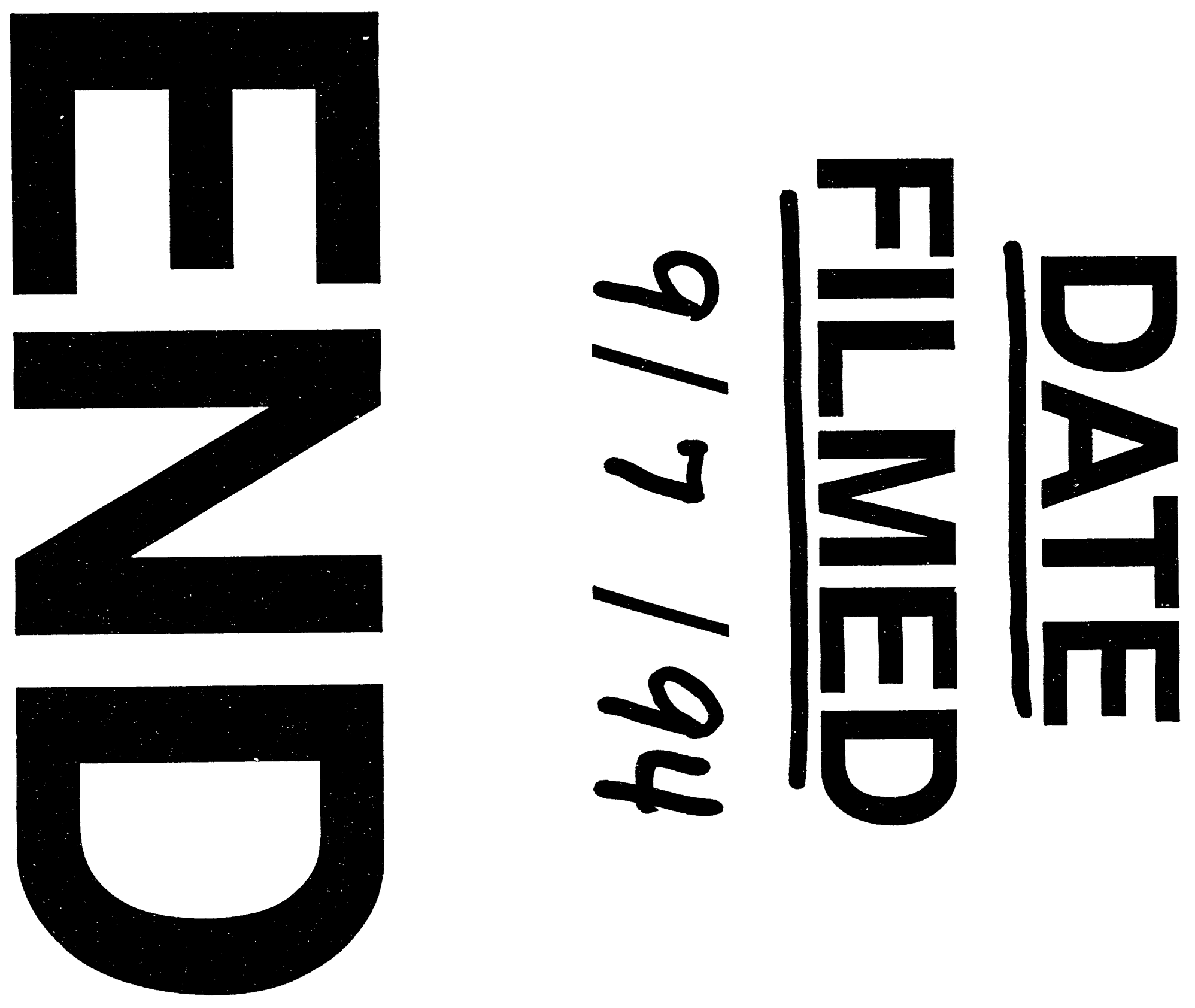
